\title{
Impact of biogenic very short-lived bromine on the Antarctic ozone hole during the 21st century
}

\author{
Rafael P. Fernandez ${ }^{1,2}$, Douglas E. Kinnison ${ }^{3}$, Jean-Francois Lamarque ${ }^{3}$, Simone Tilmes ${ }^{3}$, and Alfonso Saiz-Lopez ${ }^{1}$ \\ ${ }^{1}$ Department of Atmospheric Chemistry and Climate, Institute of Physical Chemistry Rocasolano, \\ CSIC, Madrid, 28006, Spain \\ ${ }^{2}$ National Research Council (CONICET), FCEN-UNCuyo, UNT-FRM, Mendoza, 5500, Argentina \\ ${ }^{3}$ Atmospheric Chemistry, Observations \& Modelling Laboratory, National Center for Atmospheric Research, \\ Boulder, CO 80301, USA
}

Correspondence to: Alfonso Saiz-Lopez (a.saiz@csic.es)

Received: 21 September 2016 - Published in Atmos. Chem. Phys. Discuss.: 5 October 2016

Revised: 26 December 2016 - Accepted: 9 January 2017 - Published: 3 February 2017

\begin{abstract}
Active bromine released from the photochemical decomposition of biogenic very short-lived bromocarbons $\left(\mathrm{VSL}^{\mathrm{Br}}\right.$ ) enhances stratospheric ozone depletion. Based on a dual set of 1960-2100 coupled chemistry-climate simulations (i.e. with and without $\mathrm{VSL}^{\mathrm{Br}}$ ), we show that the maximum Antarctic ozone hole depletion increases by up to $14 \%$ when natural $\mathrm{VSL}^{\mathrm{Br}}$ are considered, which is in better agreement with ozone observations. The impact of the additional 5 pptv $\mathrm{VSL}^{\mathrm{Br}}$ on Antarctic ozone is most evident in the periphery of the ozone hole, producing an expansion of the ozone hole area of $\sim 5$ million $\mathrm{km}^{2}$, which is equivalent in magnitude to the recently estimated Antarctic ozone healing due to the implementation of the Montreal Protocol. We find that the inclusion of $\mathrm{VSL}^{\mathrm{Br}}$ in CAM-Chem (Community Atmosphere Model with Chemistry, version 4.0) does not introduce a significant delay of the modelled ozone return date to 1980 October levels, but instead affects the depth and duration of the simulated ozone hole. Our analysis further shows that total bromine-catalysed ozone destruction in the lower stratosphere surpasses that of chlorine by the year 2070 and indicates that natural $\mathrm{VSL}^{\mathrm{Br}}$ chemistry would dominate Antarctic ozone seasonality before the end of the $21 \mathrm{st}$ century. This work suggests a large influence of biogenic bromine on the future Antarctic ozone layer.
\end{abstract}

\section{Introduction}

The detection of the springtime Antarctic ozone hole (Farman et al., 1985) has been one of the great geophysical discoveries of the 20th century. The unambiguous scientific reports describing the active role of halogen atoms (i.e. chlorine and bromine), released from anthropogenic chlorofluorocarbons (CFCs) and halons, in depleting stratospheric ozone (Molina and Rowland, 1974; McElroy et al., 1986; Daniel et al., 1999) led to the rapid and efficient implementation of the Montreal Protocol in 1989 (Solomon, 1999). Since then, the consequent turnover on the anthropogenic emissions of long-lived chlorine ( $\mathrm{LL}^{\mathrm{Cl}}$ ) and bromine $\left(\mathrm{LL}^{\mathrm{Br}}\right)$ sources (WMO, 2014) has controlled the evolution of the strong springtime ozone depletion within the Antarctic vortex, and the first signs of recovery of the ozone hole became evident at the beginning of the 21st century (WMO, 2014; Chipperfield et al., 2015; Solomon et al., 2016).

Several coordinated initiatives were conducted by the scientific community to predict the future evolution of the stratospheric ozone layer and its impact on climate change (Eyring et al., 2007, 2010b; Austin et al., 2010; WMO, 2014). The multi-model CCMVal-2 ozone assessment (Eyring et al., 2010a) determined that the Antarctic ozone return date to 1980 values is expected to occur around the years 2045-2060, while the impact of halogenated ozone depleting substances (ODSs, such as $\mathrm{LL}^{\mathrm{Cl}}$ and $\mathrm{LL}^{\mathrm{Br}}$ ) on stratospheric ozone photochemistry will persist until the end of the 21st century. The 2045-2060 Antarctic return date 
is currently the recommended projection within the latest Ozone Assessment Reports (WMO, 2011, 2014). A selected group of models show a later return date for Antarctic ozone (between 2070 and 2080; see WMO, 2014), although this modelled return date is subject to changes in stratospheric sulfuric aerosols and uncertainties in greenhouse gas loadings during the second half of the century. Many studies show that dynamical and chemical processes affect the size, strength and depth of the ozone hole formation (see Solomon et al., 2015 and references therein). Ongoing research within the Chemistry-Climate Model Initiative (CCMI) (Eyring et al., 2013; Hegglin et al., 2014) includes model experiments that consider, along with the dominant $\mathrm{LL}^{\mathrm{Cl}}$ and $\mathrm{LL}^{\mathrm{Br}}$ anthropogenic emissions, an additional contribution from biogenic very short-lived bromocarbons $\left(\mathrm{VSL}^{\mathrm{Br}}\right)$. This additional input of bromine is required to reconcile current stratospheric bromine trends (Salawitch et al., 2010; WMO, 2014).

$\mathrm{VSL}^{\mathrm{Br}}$ are naturally released from biologically productive waters mainly within the tropical oceans (Warwick et al., 2006; Butler et al., 2007; Kerkweg et al., 2008), where strong convective uplifts efficiently entrain near surface air into the upper troposphere and lower stratosphere (Aschmann and Sinnhuber, 2013; Liang et al., 2014; Saiz-Lopez and Fernan$\mathrm{dez}, 2016)$. The current contribution of $\mathrm{VSL}^{\mathrm{Br}}$ to total stratospheric inorganic bromine is estimated to be in the range of 3-8 pptv (Montzka et al., 2011; WMO, 2014; Navarro et al., 2015; Hossaini et al., 2016). The most accepted value for stratospheric injection is $\mathrm{VSL}^{\mathrm{Br}} \approx 5$ pptv, which currently represents approximately $30 \%$ of the total contribution from $\mathrm{LL}^{\mathrm{Br}}$ substances arising from both anthropogenic and natural origins $\left(\sim 7.8\right.$ pptv Halons $+\sim 7.2$ pptv $\mathrm{CH}_{3} \mathrm{Br} \approx 15$ 16 pptv $\mathrm{LL}^{\mathrm{Br}}$ ). The additional stratospheric contribution of biogenic $\mathrm{VSL}^{\mathrm{Br}}$ improves the model-observation agreement with respect to stratospheric ozone trends between 1980 and the present (Sinnhuber et al., 2009), with large ozonedepleting impacts during periods of high aerosol loading within mid-latitudes (Feng et al., 2007; Sinnhuber and Meul, 2015). Although we still lack a scientific consensus with respect to the future evolution of $\mathrm{VSL}^{\mathrm{Br}}$ oceanic source strength and stratospheric injection (WMO, 2014), it will probably increase in the future following the increase in sea surface temperature (SST) and oceanic nutrient supply, as well as due to the enhancement of the troposphere-tostratosphere exchange (Hossaini et al., 2012; Leedham et al., 2013).

Previous chemistry-climate modelling studies considering $\mathrm{VSL}^{\mathrm{Br}}$ chemistry mainly focused on improving the model vs. observed ozone trends at mid-latitudes with respect to equivalent set-ups considering only the dominant anthropogenic $\mathrm{LL}^{\mathrm{Cl}}$ and $\mathrm{LL}^{\mathrm{Br}}$ sources (Feng et al., 2007; Sinnhuber et al., 2009). However, those previous studies lack an in-depth timeline analysis of the $\mathrm{VSL}^{\mathrm{Br}}$ impact on the ozone hole evolution during the current century. More recently, Sinnhuber and Meul (2015) found that the impact of VSL ${ }^{\mathrm{Br}}$ maximises the Antarctic ozone hole ( $\sim 20 \%$ greater ozone de- pletion), while Oman et al. (2016) determined that the addition of 5 pptv $\mathrm{VSL}^{\mathrm{Br}}$ to the stratosphere could delay the ozone return date to 1980 levels by as much as 1 decade. Their result is in agreement with that of Yang et al. (2014), who performed present-day time slice simulations to address the sensitivity of stratospheric ozone to a speculative doubling of VSL ${ }^{\mathrm{Br}}$ sources under different $\mathrm{LL}^{\mathrm{Cl}}$ scenarios. Even when those works addressed the important question of the return date, conclusions were obtained considering a unique simulation member for each case and an approximate approach of $\mathrm{VSL}^{\mathrm{Br}}$ ocean emissions. Here, using the CAMChem model (Saiz-Lopez et al., 2012; Fernandez et al., 2014; Tilmes et al., 2015, 2016), we present a coherent ensemble of coupled (with an interactive ocean) chemistry-climate simulations from 1960 to 2100 with and without the contribution of oceanic $\mathrm{VSL}^{\mathrm{Br}}$ sources. We focus on natural VSL $\mathrm{Vr}_{-}$ driven changes in the chemical composition and evolution of the Antarctic ozone hole during the 21st century, particularly on their influence on the seasonality and enlargement of the ozone hole area, ozone hole depth and return date to 1980 levels. The analysis shown here describes the ozone hole progress distinguishing the monthly seasonality from the long-term evolution. Additionally, we present a timeline assessment of individual contribution of anthropogenic and natural chlorine and bromine species to Antarctic ozone loss during the 21 st century, recognising the independent impact arising from $\mathrm{LL}^{\mathrm{Br}}$ and $\mathrm{VSL}^{\mathrm{Br}}$ sources to the overall halogencatalysed $\mathrm{O}_{3}$ destruction.

\section{Methods}

The three-dimensional chemistry climate model CAM-Chem (Community Atmospheric Model with Chemistry, version 4.0)(Lamarque et al., 2012), included in the CESM framework (Community Earth System Model, version 1.1.1) has been used for this study. The model set-up is identical to the CCMI-REFC 2 experiment described in detail by Tilmes et al. (2016), with the exception that the current configuration includes a full halogen chemistry mechanism from the earth surface to the lower stratosphere (Fernandez et al., 2014), i.e. instead of considering a constant lower boundary condition of $1.2 \mathrm{pptv}$ for bromoform $\left(\mathrm{CHBr}_{3}\right)$ and dibromomethane $\left(\mathrm{CH}_{2} \mathrm{Br}_{2}\right)$ or increasing $\mathrm{CH}_{3} \mathrm{Br}$ by 5 pptv, our model set-up includes geographically distributed and seasonal-dependent oceanic emissions of six bromocarbons $\left(\mathrm{VSL}^{\mathrm{Br}}=\mathrm{CHBr}_{3}, \mathrm{CH}_{2} \mathrm{Br}_{2}, \mathrm{CH}_{2} \mathrm{BrCl}, \mathrm{CHBrCl}_{2}, \mathrm{CHBr}_{2} \mathrm{Cl}\right.$ and $\mathrm{CH}_{2} \mathrm{IBr}$ ) (Ordóñez et al., 2012). At the model surface boundary, zonally averaged distributions of long-lived halocarbons $\left(\mathrm{LL}^{\mathrm{Cl}}=\mathrm{CH}_{3} \mathrm{Cl}, \mathrm{CH}_{3} \mathrm{CCl}_{3}, \mathrm{CCl}_{4}\right.$, CFC-11, CFC12, CFC-113, HCFC-22, CFC-114, CFC-115, HCFC-141b, HCFC-142b and $\mathrm{LL}^{\mathrm{Br}}=\mathrm{CH}_{3} \mathrm{Br}, \mathrm{H}-1301, \mathrm{H}-1211, \mathrm{H}-1202$, and $\mathrm{H}-2402)$ based on the $\mathrm{A} 1$ halogen scenario from WMO (2011) are considered, while surface concentrations of $\mathrm{CO}_{2}, \mathrm{CH}_{4}, \mathrm{H}_{2}$ and $\mathrm{N}_{2} \mathrm{O}$ are specified following the moder- 
ate Representation Concentration Pathway 6.0 (RCP6.0) scenario (see Eyring et al., 2013, for a complete description of REFC2-CCMI set-up). In order to avoid unnecessary uncertainties associated with the speculative evolution of $\mathrm{VSL}^{\mathrm{Br}}$ oceanic emissions, we used a constant annual source strength for the whole modelled period.

CAM-Chem was configured with a horizontal resolution of $1.9^{\circ}$ latitude by $2.5^{\circ}$ longitude and 26 vertical levels, from the surface up to $\sim 40 \mathrm{~km}(\sim 3.5 \mathrm{hPa})$. The number of stratospheric levels changes depending on the location of the tropopause: within the tropics, there are eight levels above the tropopause $(\sim 100 \mathrm{hPa})$, with a mean thickness of $1.25 \mathrm{~km}(15.5 \mathrm{hPa})$ for the lower stratospheric levels and $5.2 \mathrm{~km}(3.8 \mathrm{hPa})$ between the two highest levels. Within the polar regions, the tropopause is located approximately at $\sim 300 \mathrm{hPa}$, and up to 15 model levels belong to the stratosphere. To have a reasonable representation of the overall stratospheric circulation, the integrated momentum that would have been deposited above the model top is specified by an upper boundary condition (Lamarque et al., 2008). A similar procedure is applied to the altitude-dependent photolysis rate computations, which include an upper boundary condition that considers the ozone column fraction prevailing above the model top. The current CAM-Chem version includes a non-orographic gravity wave scheme based on the inertia-gravity wave (IGW) parameterization, an internal computation of the quasi-biennial oscillation (QBO), dependent on the observed interannual variability of equatorial zonal winds, and a CCMI-based implementation of stratospheric aerosol and surface area density (see Tilmes et al., 2016, for details). The model includes heterogeneous processes for active halogen species in polar stratospheric clouds from MOZART-3 (Kinnison et al., 2007; Wegner et al., 2013). A full description of the CAM-Chem VSL configuration, detailing both natural and anthropogenic sources, heterogeneous recycling reactions, dry and wet deposition, convective uplift and large-scale transport has been given elsewhere (Ordóñez et al., 2012; Fernandez et al., 2014). This model configuration uses a fully coupled Earth System Model approach, i.e. the ocean and sea ice are explicitly computed. More details of CAM-Chem performance at reproducing changes in dynamics and chemical composition of the stratosphere are given in the Supplement.

Two ensembles of independent experiments (each of them with three individual ensemble members only differing in their 1950 initial atmospheric conditions) were performed from 1960 to 2100 considering a 10-year spin-up to allow for stratospheric circulation stabilisation (i.e. each simulation started in 1950). Note that our REFC2 set-up includes volcanic eruptions in the past, but possible volcanic eruptions in the future are not considered since they cannot be known in advance (Eyring et al., 2013). The baseline set-up (run ${ }^{\mathrm{LL}}$ ) considered only the halogen $\mathrm{LL}^{\mathrm{Cl}}$ and $\mathrm{LL}^{\mathrm{Br}}$ contribution from anthropogenic CFCs, hydrochlorofluorocarbons (HCFCs), halons and methyl chloride and methyl bromide; while the second set of simulations included, in addition to the run ${ }^{\mathrm{LL}}$ sources, the background biogenic contribution from $\mathrm{VSL}^{\mathrm{Br}}$ oceanic sources (run ${ }^{\mathrm{LL}}+\mathrm{VSL}$ ). Differences between these two types of experiments allow quantification of the overall impact of natural $\mathrm{VSL}^{\mathrm{Br}}$ sources on stratospheric ozone. Please note that whenever we refer to "natural" contribution, we are pointing to the contribution of biogenic $\mathrm{VSL}^{\mathrm{Br}}$ under a background stratospheric environment due to the dominant anthropogenic $\mathrm{LL}^{\mathrm{Cl}}$ and $\mathrm{LL}^{\mathrm{Br}}$ sources (i.e. the natural fractions of long-lived chlorine and bromine are minor).

Unless stated otherwise, all figures were generated considering the ensemble average ( $\operatorname{sim}^{\text {ens }}$ ) of each independent experiment (run ${ }^{\mathrm{LL}}$ and run ${ }^{\mathrm{LL}}+\mathrm{VSL}$ ), which in turn were computed considering the mean of the three independent simulations $\left(\operatorname{sim}^{004}, \operatorname{sim}^{005}\right.$ and $\left.\operatorname{sim}^{006}\right)$. For the case of vertical profiles and latitudinal variations, the zonal mean of each ensemble was computed to the monthly output before processing the data, while a Hamming filter with an 11-year window was applied to all long-term time series to smooth the data. Most of the figures and values within the text include geographically averaged quantities within the southern polar cap (SP), defined as the region poleward of $63^{\circ} \mathrm{S}$. For the case of the ozone hole area, we use the definition from the NASA Goddard Space Flight Center (GSFC), defined as the region with ozone columns below 220 DU located south of $40^{\circ} \mathrm{S}$ (https://ozonewatch.gsfc.nasa. gov/meteorology/SH.html). Model results were compared to the National Institute for Water and Atmospheric Research Bodeker Scientific (NIWA-BS) total column ozone database (version 2.8), which combines measurements from a number of different satellite-based instruments between 1978 and 2012 (Bodeker et al., 2005, http://www.bodekerscientific. com/data/total-column-ozone).

\section{Results and discussion}

\subsection{Contribution of $L L^{B r}$ and $V S L^{B r}$ to stratospheric bromine}

The 1960-2100 global evolution of the stratospheric chlorine and bromine loading is shown in Fig. 1. The dominant anthropogenic $\mathrm{LL}^{\mathrm{Cl}}$ and $\mathrm{LL}^{\mathrm{Br}}$ scenarios included in our REFC2 simulations (Tilmes et al., 2016) show a pronounced peak at the end of the 20th century and beginning of the 21 st century, respectively after which both their abundances decline. The respective stratospheric abundances for $\mathrm{LL}^{\mathrm{Cl}}$ and $\mathrm{LL}^{\mathrm{Br}}$ for 2012 are approximately $3260 \mathrm{ppbv}$ and $15.4 \mathrm{pptv}$, which are in excellent agreement with the last WMO (2014) report. In comparison, the evolution of $\mathrm{VSL}^{\mathrm{Br}}$ sources remains constant in time, with a presentday fixed contribution of $\sim 5 \mathrm{pptv}$ (Ordóñez et al., 2012). Added together, $\mathrm{LL}^{\mathrm{Br}}+\mathrm{VSL}^{\mathrm{Br}}$ show a stratospheric abundance of $\sim 20.4$ pptv at present time, in line with Fernan- 


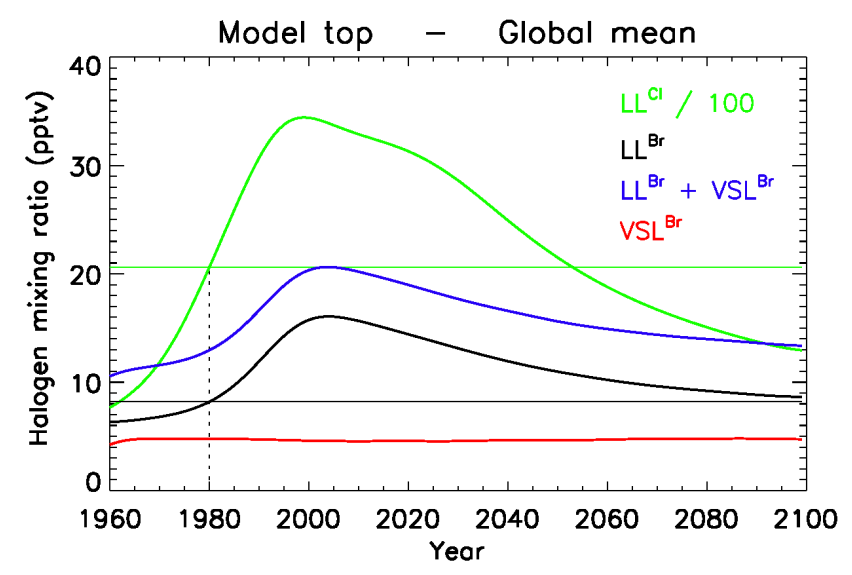

Figure 1. Temporal evolution of the annual mean global stratospheric halogen loading at the top of the model (i.e. $3.5 \mathrm{hPa}$ ) for long-lived chlorine $\left(\mathrm{LL}^{\mathrm{Cl}}\right)$ and bromine $\left(\mathrm{LL}^{\mathrm{Br}}\right)$, as well as very short-lived bromine $\left(\mathrm{VSL}^{\mathrm{Br}}\right)$. The horizontal lines indicate the $\mathrm{LL}^{\mathrm{Cl}}$ and $\mathrm{LL}^{\mathrm{Br}}$ mixing ratio for $1980 . \mathrm{LL}^{\mathrm{Cl}}$ mixing ratios were divided by 100 .

dez et al. (2014), who validated CAM-Chem bromine abundances and stratospheric injection for the year 2000 based on a multiple set of specified dynamics (SD) simulations. Note that stratospheric $\mathrm{LL}^{\mathrm{Cl}}$ returns to its past 1980 levels before 2060, while the 1980 loading of $L^{B r}$ is not recovered even by the end of the 21 st century. Even when biogenic VSL ${ }^{\mathrm{Br}}$ sources remain constant, their relative contribution to the total bromine stratospheric loading changes with time; while for the year $2000 \mathrm{VSL}^{\mathrm{Br}}$ represents $\sim 24 \%$ of total bromine, by the end of the 21 st century it reaches $40 \%$ of stratospheric bromine within our current emission scenario. These values are likely lower limits of the percentage contribution of biogenic sources to stratospheric bromine, as predicted increases in SST and oceanic nutrient supply are expected to enhance the biological activity and $\mathrm{VSL}^{\mathrm{Br}}$ production within the tropical oceans (Hossaini et al., 2012; Leedham et al., 2013). Furthermore, the increase in SST and atmospheric temperature projected for the 21 st century is expected to produce a strengthening of the convective transport within the tropics (Hossaini et al., 2012; Braesicke et al., 2013; Leedham et al., 2013), which could enhance the stratospheric injection of $\mathrm{VSL}^{\mathrm{Br}}$. Knowledge of the extent at which the inorganic fraction of $\mathrm{VSL}^{\mathrm{Br}}$ is being injected into the stratosphere is of great importance since it strongly affects the ozone levels mostly in the lowermost stratosphere (Salawitch et al., 2005; Fernandez et al., 2014), which has implications at the altitudes where the strongest $\mathrm{O}_{3}$-mediated radiative forcing changes due to greenhouse gases are expected to occur (Bekki et al., 2013). Note that the atmospheric burden of the inorganic bromine portion in the tropical tropopause layer is highly dependent on the competition between heterogeneous recycling reactions, evaporation and washout processes oc-
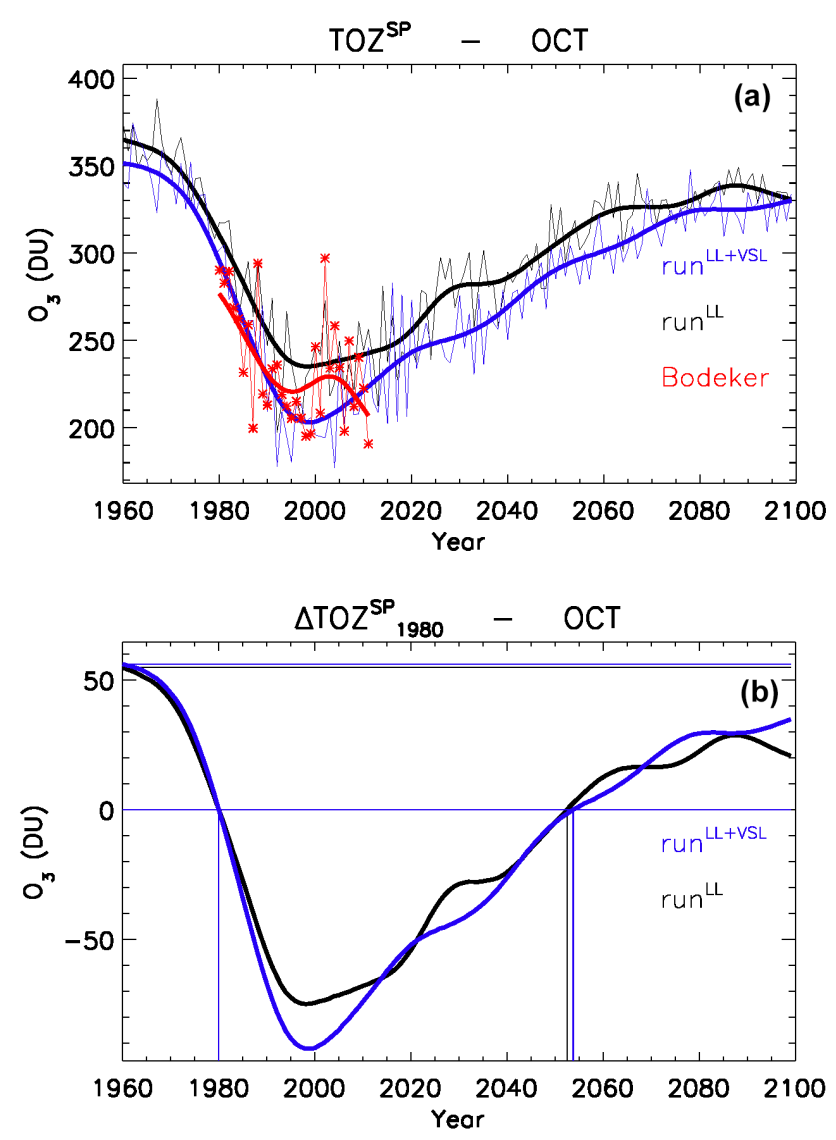

Figure 2. Temporal evolution of the total ozone column averaged within the southern polar cap ( $\mathrm{TOZ}^{\mathrm{SP}}$ ) during October. CAM-Chem results are shown in blue for run ${ }^{\mathrm{LL}+\mathrm{VSL}}$ and black for run ${ }^{\mathrm{LL}}$. (a) Absolute $\mathrm{TOZ}^{\mathrm{SP}}$ values for the ensemble mean (thin lines) and the 11-year smooth time series (thick lines). Red lines and symbols show merged satellite and ground base measurements from the Bodeker database averaged within the same spatial and temporal mask as the model output. (b) Total ozone column adjusted with respect to October $1980\left(\Delta \mathrm{TOZ}_{1980}^{\mathrm{SP}}=\mathrm{TOZ}_{\mathrm{year}}^{\mathrm{SP}}-\mathrm{TOZ}_{1980}^{\mathrm{SP}}\right)$. The zero horizontal line indicates the October $\Delta \mathrm{TOZ}_{1980}^{\mathrm{SP}}$ column for each experiment, while their respective return dates to 1980 are shown by the vertical lines. The upper horizontal lines represent the $\mathrm{TOZ}^{\mathrm{SP}}$ column during October 1960 for run ${ }^{\mathrm{LL}}+\mathrm{VSL}$ and run ${ }^{\mathrm{LL}}$. Equivalent figures for each independent simulation are shown in the Supplement.

curring on the surface of ice crystals (Aschmann et al., 2011; Fernandez et al., 2014).

\subsection{Impact of $\mathrm{VSL}^{\mathrm{Br}}$ on the ozone hole evolution and its return date}

The 1960-2100 evolution of the total ozone column within the southern polar cap ( $\mathrm{TOZ}^{\mathrm{SP}}$, between $63^{\circ}$ and $90^{\circ} \mathrm{S}$ ) during October is illustrated in Fig. 2. Biogenic $\mathrm{VSL}^{\mathrm{Br}}$ introduce a continuous reduction in $\mathrm{TOZ}^{\mathrm{SP}}$ that exceeds the model ensemble variability between run $^{\mathrm{LL}}$ and run $^{\mathrm{LL}}+\mathrm{VSL}$ exper- 
Table 1. Estimation of the ozone return date, minimum ozone column within the southern polar cap (TOZ $\mathrm{min}_{\text {) }}^{\mathrm{SP}}$ and the maximum ozone hole area $\left(\mathrm{OHA}_{\max }\right)$ modelled with CAM-Chem for different simulations and ensemble members.

\begin{tabular}{|c|c|c|c|c|c|c|}
\hline & \multicolumn{2}{|c|}{ Return date ${ }^{1980}$ (years) } & \multicolumn{2}{|c|}{$\mathrm{TOZ}_{\min }^{\mathrm{SP}}(\mathrm{DU})$} & \multicolumn{2}{|c|}{$\mathrm{OHA}_{\max }\left(\right.$ million $\left.\mathrm{km}^{2}\right)$} \\
\hline & $\operatorname{run}^{\mathrm{LL}}+\mathrm{VSL}$ & $\operatorname{run}^{\mathrm{LL}}$ & $\operatorname{run}^{\mathrm{LL}}+\mathrm{VSL}$ & $\operatorname{run}^{\mathrm{LL}}$ & $\operatorname{run}^{\mathrm{LL}}+\mathrm{VSL}$ & $\operatorname{run}^{\mathrm{LL}}$ \\
\hline $\operatorname{sim}^{004}$ & 2058.9 & 2053.4 & -88.9 & -72.8 & 19 & 14.2 \\
\hline $\operatorname{sim}^{005}$ & 2053.4 & 2052.2 & -98.1 & -72.8 & 20.8 & 13.8 \\
\hline $\operatorname{sim}^{006}$ & 2049.3 & 2052.3 & -90.7 & -85.8 & 20.3 & 15 \\
\hline $\begin{array}{l}\text { Ensemble } \\
\text { Shift }\end{array}$ & $\begin{array}{r}2053.9 \pm 4.8 \\
(1.2=\end{array}$ & $\begin{array}{l}2052.7 \pm 0.7 \\
5.5)\end{array}$ & $\begin{array}{r}-92.6 \pm 4.9 \\
(-15.4\end{array}$ & $2 \pm 7.5$ & $\begin{array}{r}20.0 \pm 0.9 \\
\quad(5.7 \pm\end{array}$ & $\begin{array}{l}14.3 \pm 0.6 \\
.5)\end{array}$ \\
\hline
\end{tabular}

iments and improves the overall model-satellite agreement (Fig. 2a). An individual panel for each independent simulation is shown in the Supplement. The temporal location of the minimum $\mathrm{TOZ}^{\mathrm{SP}}$ occurs simultaneously at the beginning of the 21 st century in both experiments, with a minimum October mean $\mathrm{TOZ}^{\mathrm{SP}}$ column of 205 and $235 \mathrm{DU}$ for run ${ }^{\mathrm{LL}}+\mathrm{VSL}$ and run $^{\mathrm{LL}}$ respectively. This leads to a maximum October $\mathrm{TOZ}^{\mathrm{SP}}$ difference of $-30 \mathrm{DU}$ or $\sim 14 \%$ of the overall $\mathrm{TOZ}^{\mathrm{SP}}$ during 2003, while before 1970 the ozone differences remain practically constant and smaller than $-14 \mathrm{DU}$, which represents only $\sim 3.5 \%$ of $\mathrm{TOZ}^{\mathrm{SP}}$. Analysis of the global annual column (TOZ ${ }^{\mathrm{GB}}$ ) between model experiments during the 1960-2100 interval shows approximately $-3.6 \mathrm{DU}$ difference, with maximum changes reaching $-5.2 \mathrm{DU}$ by 1995. This represents $<2 \%$ of the annual $\mathrm{TOZ}^{\mathrm{GB}}$ observed for present time conditions and lies within the lower range of previous modelling studies for tropical and mid-latitudes over the 1960-2005 period (Sinnhuber and Meul, 2015). These calculations reveal a much larger ozone loss efficiency of $\mathrm{VSL}^{\mathrm{Br}}$ in the Antarctic ozone layer than in global or tropical ozone stratospheric trends.

The different stratospheric bromine loading between run $^{\mathrm{LL}}+\mathrm{VSL}$ and run ${ }^{\mathrm{LL}}$ produces a different ozone column since the very beginning of the modelled period. The $\Delta \mathrm{TOZ}_{1980}^{\mathrm{SP}}$ (i.e. the difference with respect to 1980 baseline levels) during October shows a minimum for 2003 of -92 and $-77 \mathrm{DU}$ for run ${ }^{\mathrm{LL}+\mathrm{VSL}}$ and run $^{\mathrm{LL}}$ respectively (Fig. 2b). Hence, from the $30 \mathrm{DU}$ absolute difference shown in Fig. 2a, approximately half of the ozone offset is introduced by the background contribution of $\mathrm{VSL}^{\mathrm{Br}}$ on the global pre-ozone hole stratosphere. The additional ozone hole depletion ( $\sim 15 \mathrm{DU}$ by 2000 ) induced by $\mathrm{VSL}^{\mathrm{Br}}$ is more noticeable between 1990 and 2010, i.e. when the stratospheric $\mathrm{LL}^{\mathrm{Cl}}$ loading also maximises (see Fig. 1). This result is in agreement with Sinnhuber and Meul (2015), who reported a faster initial decrease and an overall better agreement between past mid-latitude $\mathrm{O}_{3}$ trends and a model simulation forced with the additional contribution from $\mathrm{VSL}^{\mathrm{Br}}$ sources. Much smaller impacts are modelled on the second quarter of the century when $\mathrm{LL}^{\mathrm{Cl}}$ constantly decreases and other ODSs (such as $\mathrm{CH}_{4}$ and $\mathrm{N}_{2} \mathrm{O}$ ) increase.
The vertical lines in Fig. $2 b$ indicate that the expected $\mathrm{TOZ}^{\mathrm{SP}}$ return date to October 1980 is approximately the same for both experiments: individual computations of the return date considering each of the independent ensemble members show that the expected return date shift due to $\mathrm{VSL}^{\mathrm{Br}}$ lies within model uncertainties (Table 1), with mean ensemble values of $\sim 2052.7 \pm 0.7$ for run $^{\mathrm{LL}}$ and $\sim 2053.9 \pm 4.8$ for run ${ }^{\mathrm{LL}+V S L}$. In contrast, the maximum $\mathrm{TOZ}^{\mathrm{SP}}$ depletion observed for 2000 increases by $-15.4 \pm 12.4 \mathrm{DU}$ when $\sim 5 \mathrm{pptv}$ of natural bromine is included, which exceeds the model internal variability. Thus, the Antarctic ozone hole return date, determined following the standard computation relative to the ozone column existent in October 1980 (Eyring et al., 2010a, b), is not significantly affected by the inclusion of natural $\mathrm{VSL}^{\mathrm{Br}}$ sources. This result contradicts the recent findings from Yang et al. (2014) and Oman et al. (2016), who estimated an increase between 7 and 10 years in the ozone hole return date when $\mathrm{VSL}^{\mathrm{Br}}$ values are considered. Note, however, that the former study performed non-coupled (without an interactive ocean) time slice simulations, including a speculative doubling of $\mathrm{VSL}^{\mathrm{Br}}$ sources on top of background $\mathrm{LL}^{\mathrm{Cl}}$ and $\mathrm{LL}^{\mathrm{Br}}$ levels representative of the years 2000 and 2050, while Oman et al. (2016) considered a single member climatic simulation for each type of experiment and thus lack an assessment of the internal model variability. Indeed, our CAM-Chem results show that the range in the return dates for the different ensemble members of run ${ }^{\mathrm{LL}}+\mathrm{VSL}$ can be almost 10 years (i.e. of the same magnitude as the $\mathrm{VSL}^{\mathrm{Br}}$ enlargement suggested by previous studies), highlighting the importance of considering a multi-member ensemble mean when performing a future return date computation. Note that the return date shift for each individual simulation varies randomly independently of considering or not the smoothing filter (see Figs. S2 and S3 in the Supplement). Moreover, the inclusion of $\sim 5 \mathrm{pptv}$ of biogenic bromine does not only affect the future evolution of the ozone layer, but it also reduces the overall background stratospheric ozone column prevailing in 1980. Hence, the additional depletion of $\mathrm{VSL}^{\mathrm{Br}}$ on ozone hole columns at their maximum depth shown in Fig. 2b considers the background impact of $\mathrm{VSL}^{\mathrm{Br}}$ chemistry on polar 

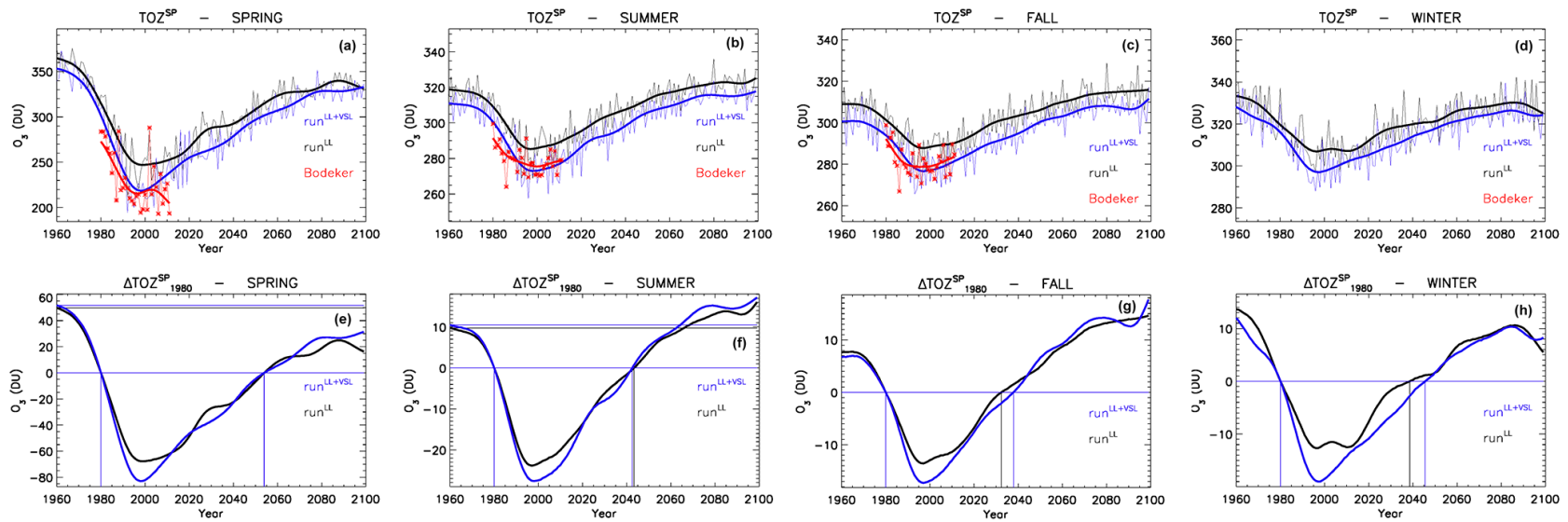

Figure 3. The same as Fig. 2 but computing the average for (a, e) spring (defined as September-October), (b, f) summer (January-February), (c, g) autumn (March-April) and (d, h) winter (June-July). The monthly output for the periods where a strong dynamical transition between seasons exists has not been considered (see text for details).

(a)
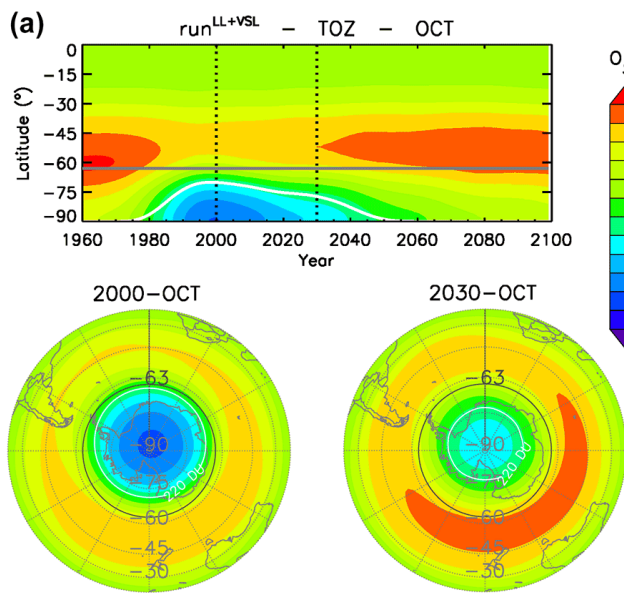

(c)
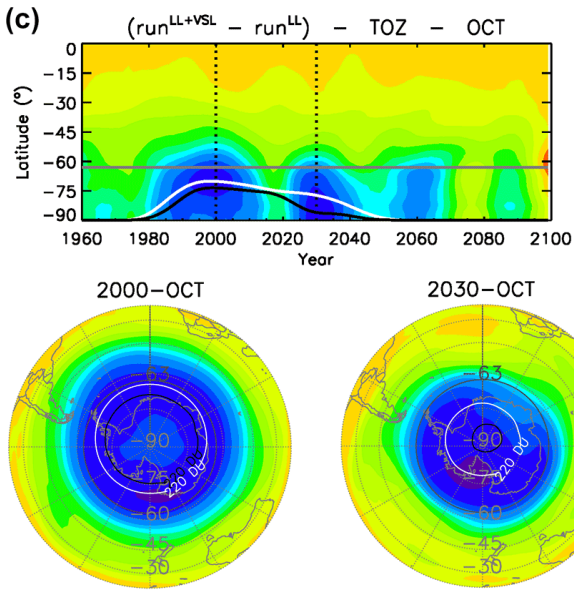

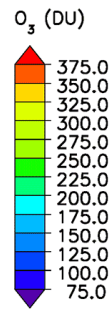

(b)

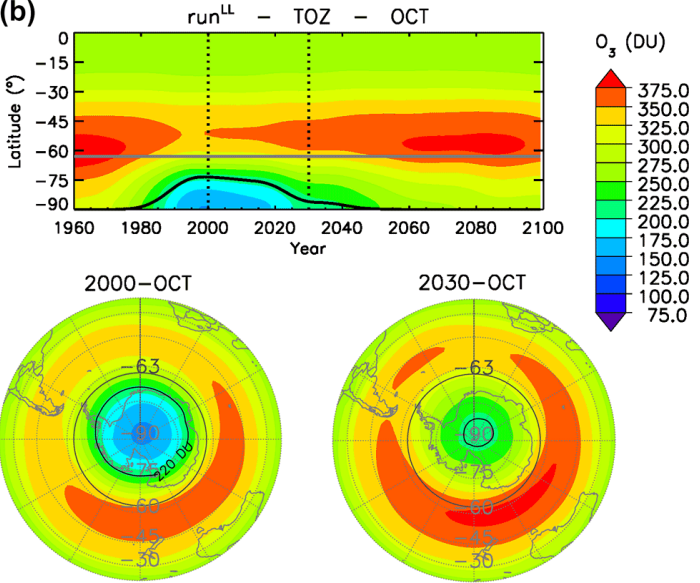

(d)
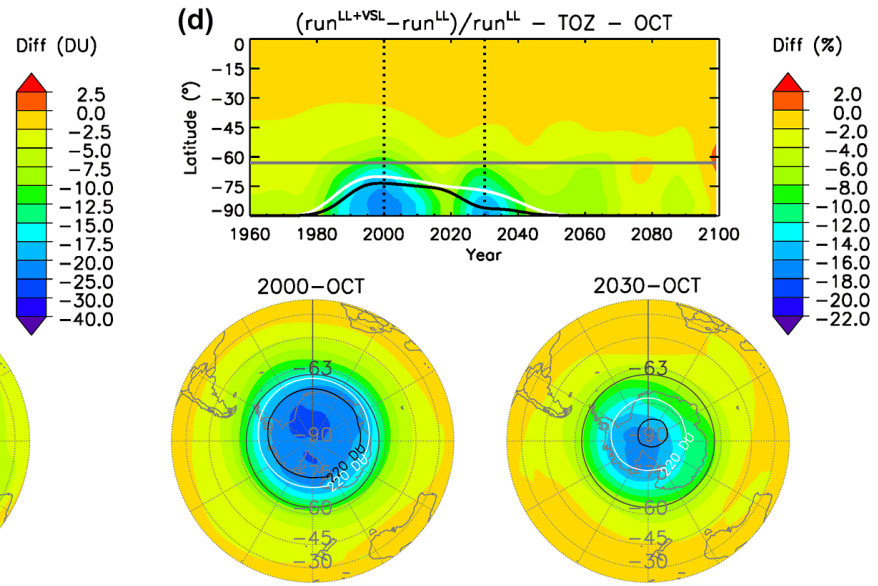

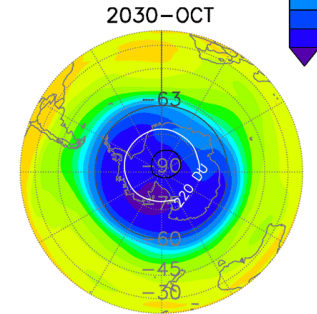

Figure 4. Ensemble mean of temporal evolution of southern hemispheric October TOZ as a function of latitude for (a) run ${ }^{\mathrm{LL}}+\mathrm{VSL}$, (b) run ${ }^{\mathrm{LL}}$, (c) absolute difference between run ${ }^{\mathrm{LL}}+\mathrm{VSL}$ and run ${ }^{\mathrm{LL}}$ and (d) percentage difference between experiments. The double inset at the bottom of each panel shows the October TOZ mean polar view during the 2000th (1995-2005 mean, left) and 2030th (2025-2035 mean, right) decades. The solid lines in each panel show the $\mathrm{O}_{3}=220$ DU limit defining the ozone hole area (GSFC, NASA) for each simulation (white for run ${ }^{\mathrm{LL}}+\mathrm{SL}$ and black for run ${ }^{\mathrm{LL}}$ ), while the solid grey lines show the $63^{\circ} \mathrm{S}$ parallel defining the southern polar cap (SP) over which TOZ $\mathrm{SP}$ is computed. 

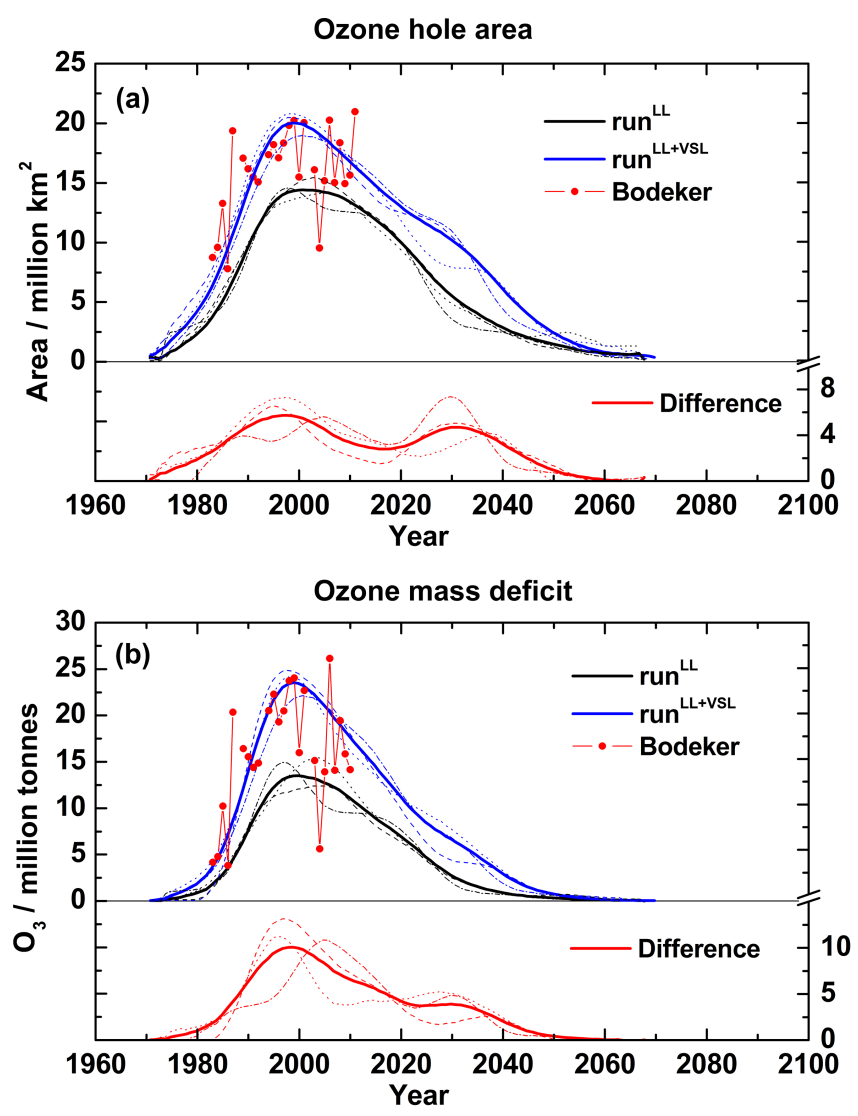

Figure 5. Temporal evolution of the ozone hole area (a) and ozone mass deficit (b) for both experiments (black for run ${ }^{\mathrm{LL}}$ and blue for run $^{\mathrm{LL}}+\mathrm{VSL}$ ) on the left axis, as well as the difference between runs (red) on the right axis. Solid thick lines show the ensemble mean for each experiment, while the dashed, dotted and dashed-dotted thin lines correspond to each of the three independent simulations $\left(\operatorname{sim}^{004}, \operatorname{sim}^{005}\right.$ and $\left.\operatorname{sim}^{006}\right)$ for each run.

stratospheric ozone throughout the 20th century, before and after the Antarctic ozone hole formed.

Agreement between the model and observations for $\mathrm{TOZ}^{\mathrm{SP}}$ and $\triangle \mathrm{TOZ}_{1980}^{\mathrm{SP}}$ improves for all seasons when $\mathrm{VSL}^{\mathrm{Br}}$ are considered (Fig. 3). To highlight the additional chemical destruction of Antarctic ozone due to biogenic bromine, the monthly output for those months where ozone depletion was dynamically controlled by the polar vortex formation and breakage (i.e. August and November-December respectively) were discarded. The maximum ozone difference between $\operatorname{run}^{\mathrm{LL}}$ and run $^{\mathrm{LL}}+\mathrm{VSL}$ is smaller than 10 and $5 \mathrm{DU}$ for summer and autumn respectively highlighting the much larger ozone depleting efficiency of the additional bromine from $\mathrm{VSL}^{\mathrm{Br}}$ sources during spring, when halogen chemistry dominates Antarctic ozone depletion. In all cases, the ozone return dates to 1980 seasonal $\mathrm{TOZ}^{\mathrm{SP}}$ columns lay within the model uncertainties, with shorter return dates observed for the summer $(\sim 2045)$ and autumn $(<2040)$. Note also that the predicted springtime $\Delta \mathrm{TOZ}_{1980}^{\mathrm{SP}}$ will not return to their
1960 values by the end of the 21 st century for either run ${ }^{\mathrm{LL}}$ or run ${ }^{\mathrm{LL}+\mathrm{VSL}}$ simulations (Figs. $2 \mathrm{~b}$ and 3 ). However, during autumn, positive $\Delta \mathrm{TOZ}_{1980}^{\mathrm{SP}}$ values are reached already by 2040 , highlighting the different future seasonal behaviour of the Antarctic stratosphere (see Sect. 3.3).

\subsubsection{Influence on the ozone hole area}

We now turn to the effect of biogenic bromine on the Antarctic ozone hole area (OHA). Figure 4 indicates that the inclusion of $\mathrm{VSL}^{\mathrm{Br}}$ produces total ozone reductions larger than $10 \mathrm{DU}$ from 1970 to 2070 . This enhanced depletion extends well outside the limits of the southern polar cap $\left(63^{\circ} \mathrm{S}\right)$ and into the mid-latitudes (see grey line in Fig. 4). Most notably, the maximum ozone depletion driven by biogenic bromine is not located at the centre of the ozone hole but on the ozone hole periphery, close to the outer limit of the polar vortex (see polar views in Fig. 4). This result has implications for assessments of geographical regions exposed to UV-B radiation: natural $\mathrm{VSL}^{\mathrm{Br}}$ leads to a total column ozone reduction between 20 and $40 \mathrm{DU}$ over wide regions of the Southern Ocean near the bottom corner of South America and New Zealand.

Figure 5 indicates that the inclusion of $\mathrm{VSL}^{\mathrm{Br}}$ produces an extension of the maximum OHA of $\sim 40 \%$ by the time when the maximum ozone hole is formed (2000th decade, 1995-2005), and it almost doubles the ozone hole extension during the 2030th decade (2025-2035). However, the inclusion of $\mathrm{VSL}^{\mathrm{Br}}$ drives a significantly lower impact on OHA by the time when the ozone return date to October 1980 is expected to occur (2050th decade: 2045-2055). The agreement with the monthly mean ozone mass deficit (OMD) and OHA values obtained from the NIWA-BS database (Bodeker et al., 2005 ) is largely improved when $\mathrm{VSL}^{\mathrm{Br}}$ are considered (nonsmoothed output for each independent simulation is shown in the Supplement). Most notably, the inclusion of $\mathrm{VSL}^{\mathrm{Br}}$ produces a maximum enlargement of the daily $\mathrm{OHA}$ larger than 5 million $\mathrm{km}^{2}$, with a consequent enhancement of $\sim 8$ million tonnes to the OMD. Thus, the biogenic bromine-driven OHA enlargement is of equivalent magnitude but opposite sign to the chemical healing shrinkage estimated due to the current phase out of $\mathrm{LL}^{\mathrm{Cl}}$ and $\mathrm{LL}^{\mathrm{Br}}$ emissions imposed by the Montreal Protocol (Solomon et al., 2016).

Unlike the 1980-baseline ozone return date definition (which is normalised to a preceding but independent ozone column for each ensemble), the OHA and OMD definitions are computed relative to a fixed value of $220 \mathrm{DU}$. Consequently, the run ${ }^{\mathrm{LL}}+\mathrm{VSL}$ experiment shows larger ozone hole areas (white line in Fig. 4) and ozone mass deficits but does not represent any significant extension to the size of the ozone hole by the time when the 1980-return date occurs. This supports the fact that the 1980-return date is controlled by the future evolution of the dominant $\mathrm{LL}^{\mathrm{Cl}}$ and $\mathrm{LL}^{\mathrm{Br}}$ sources. Note, however, that significant ozone depletion as large as $-20 \mathrm{DU}$, and for latitudes as low as $60^{\circ} \mathrm{S}$, 
(a)

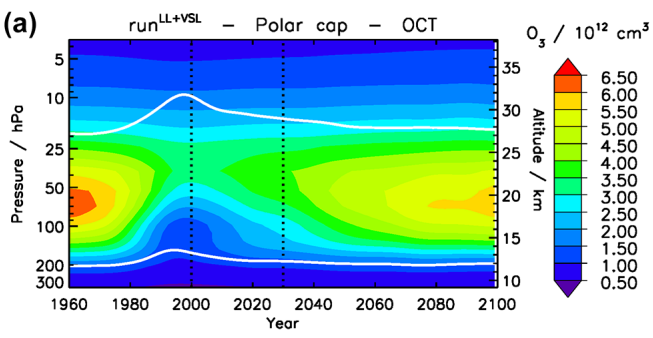

$2000-0 C T$
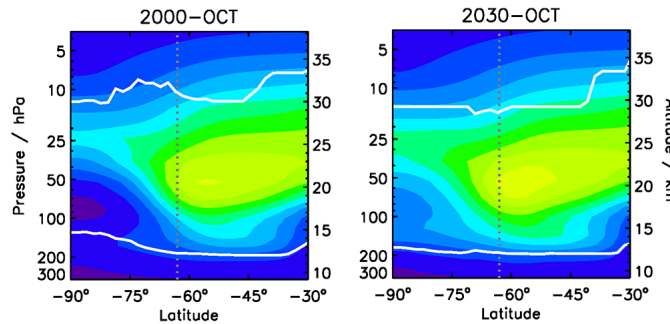

(c)

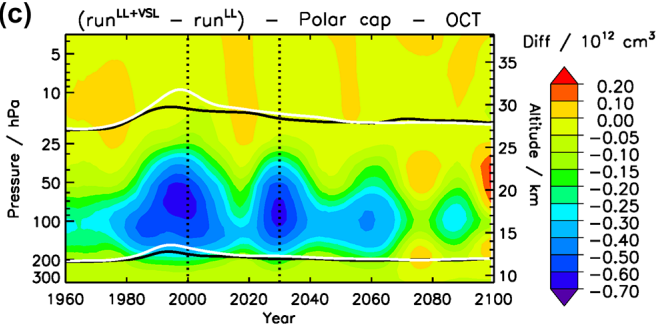

2000-OCT

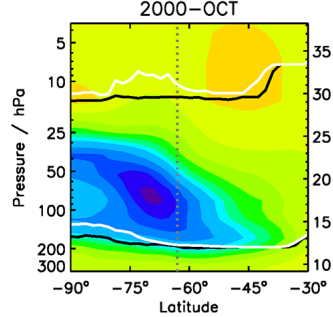

2030-OCT

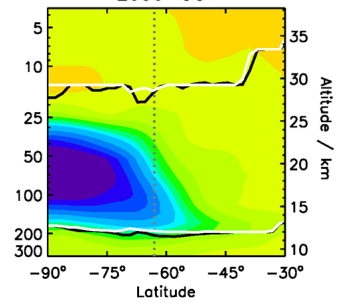

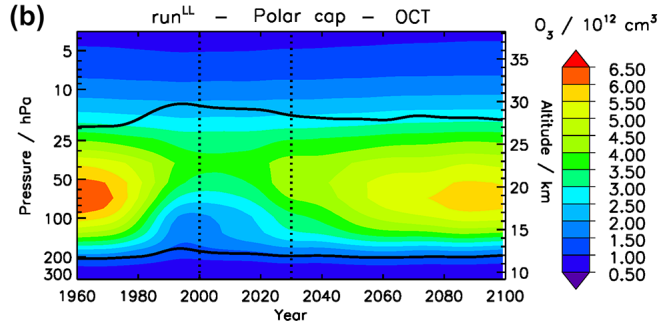
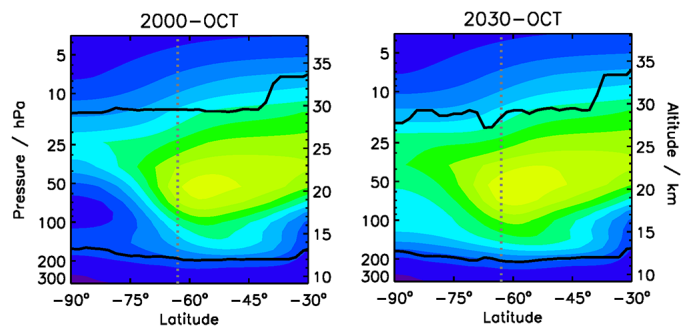

(d)

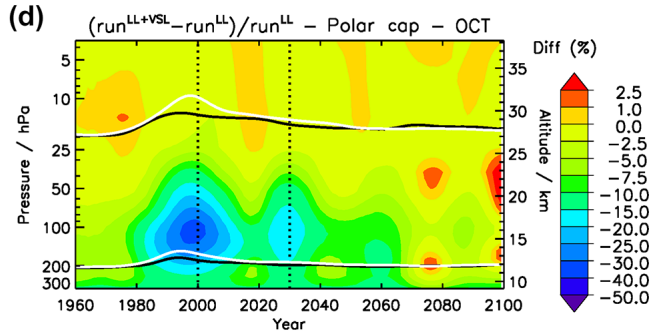

2000-OCT
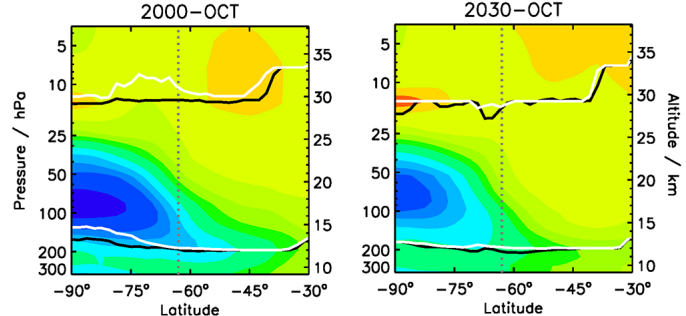

Figure 6. Temporal evolution of the ozone vertical profile averaged within the southern polar cap $\left(\mathrm{O}_{3}(z)^{\mathrm{SP}}\right)$ for the month of October for (a) run ${ }^{\mathrm{LL}}+\mathrm{VSL}$, (b) run ${ }^{\mathrm{LL}}$, (c) the absolute difference between experiments and (d) the percentage difference. The double inset at the bottom of each panel shows the October zonal mean vertical distributions during the 2000th (1995-2005 mean, left) and 2030th (2025-2035 mean, right) decades. All panels show ozone number densities (i.e. molecule $\mathrm{cm}^{-3}$ ) to highlight their contribution to the overall TOZ column. The lower solid line (white for run ${ }^{\mathrm{LL}}+\mathrm{VSL}$ and black for run ${ }^{\mathrm{LL}}$ ) indicates the location of the tropopause, while the higher solid line indicates the height where $\mathrm{O}_{3}$ number density equals its value at the tropopause.

is still observed during 2060, i.e. after the standard 1980return date has been reached. This indicates that the contribution from $\mathrm{VSL}^{\mathrm{Br}}$ has significant implications for the baseline polar stratospheric ozone chemistry aside from the abovementioned impacts on ozone hole size, depth and return date.

\subsubsection{Vertical distribution of the ozone hole depth}

Timeline analysis of the mean October ozone vertical profile within the southern polar cap $\left[\mathrm{O}_{3}(z)^{\mathrm{SP}}\right]$ is presented in Fig. 6. Typically, the deepest $\mathrm{O}_{3}(z)^{\mathrm{SP}}$ reduction occurs in the lowermost stratosphere, i.e. between 200 and $100 \mathrm{hPa}$ $(\sim 12$ and $16 \mathrm{~km}$ ), while during the pre- and post-ozone hole era, $\mathrm{O}_{3}(z)^{\mathrm{SP}}$ number densities peak between 100 and
$50 \mathrm{hPa}(\sim 16$ and $20 \mathrm{~km})$. The additional $\mathrm{O}_{3}(z)^{\mathrm{SP}}$ depletion due to $\mathrm{VSL}^{\mathrm{Br}}$ sources is maximised precisely at the same altitudes where the minimum $\mathrm{O}_{3}$ number densities are found: during the 2000th decade $\mathrm{O}_{3}(z)^{\mathrm{SP}}$ densities at $100 \mathrm{hPa}$ for $\operatorname{run}^{\mathrm{LL}+\mathrm{VSL}}$ and run $^{\mathrm{LL}}$ are respectively $<1.5$ and $<2.5 \times$ $10^{12}$ molecule $\mathrm{cm}^{-3}$, which represents $\sim 40 \%$ enhancement of the local ozone loss. This is in agreement with the recent findings reporting that near-zero ozone concentrations in the deep Antarctic lower stratospheric polar vortex are only simulated when the VSL bromine sources are included (Oman et al., 2016). Interestingly, greater ozone loss is found in the periphery of the polar vortex, and below $25 \mathrm{hPa}$, due to the larger ozone number densities prevailing at those locations 
(see zonal panel in Fig. 6c). Above $25 \mathrm{hPa}, \mathrm{O}_{3}(z)^{\mathrm{SP}}$ is not significantly modified, with an overall $\mathrm{VSL}^{\mathrm{Br}}$ impact on ozone abundances smaller than $5 \%$. This can be explained by the varying importance of bromine and chlorine chemistry at different altitudes (see Sect. 3.4). Further analysis of Fig. 6d reveals that differences larger than $25 \%$ at $\sim 100 \mathrm{hPa}$ are only found between 1990 and 2010, confirming that the strongest impact of $\mathrm{VSL}^{\mathrm{Br}}$ sources occurs coincidentally with maximum LL ${ }^{\mathrm{Cl}}$ loadings (Fig. 1).

During the simulation period (i.e. 1960-2100), $\mathrm{O}_{3}(z)^{\mathrm{SP}}$ densities below $100 \mathrm{hPa}$ are at least $10 \%$ lower for run $^{\mathrm{LL}}+\mathrm{VSL}$ than for run ${ }^{\mathrm{LL}}$. By 2050, when the 1980 October return date is approximately expected to occur, the uppermost portion of the $\mathrm{O}_{3}$ layer (above $50 \mathrm{hPa}$ ) shows strong signals of recovery and drives the overall $\mathrm{TOZ}^{\mathrm{SP}}$ return date, but the $\mathrm{O}_{3}$ abundance below $50 \mathrm{hPa}$ is still depleted relative to their pre-ozone hole era, mostly at high latitudes (Fig. 6d). It is only after 2080 that the $\mathrm{O}_{3}(z)^{\mathrm{SP}}$ vertical profile is consistent with the pre-ozone hole period, although $\mathrm{O}_{3}$ densities above $6 \times 10^{12}$ molecule $\mathrm{cm}^{-3}$ are still not recovered even by the end of the century (Fig. 6a, b). Between 2080 and 2100 , inclusion of $\mathrm{VSL}^{\mathrm{Br}}$ still represents a $10 \%$ additional $\mathrm{O}_{3}$ reduction at $100 \mathrm{hPa}$, which can be explained considering a shift from the predominant ozone destruction by chlorine to a bromine-driven depletion (whose efficiency is increased by the additional VSL ${ }^{\mathrm{Br}}$; see Sect. 3.4).

\subsection{Seasonal evolution of stratospheric Antarctic ozone}

Figure 7 shows how the seasonal cycle of $\mathrm{TOZ}^{\mathrm{SP}}$ has changed during the modelled period, expanding from the typical solar-driven natural annual cycle prevailing in 1960 (Fig. 7a) to the strongly perturbed anthropogenic-induced cycle consistent with the formation of the Antarctic ozone hole (Fig. 7c, year 2000). $\Delta$ TOZ $_{\text {July }}^{\text {SP }}$ normalisation in Figs. 7 and 8 was computed in respect to the $\mathrm{TOZ}^{\mathrm{SP}}$ value in July of each year; therefore, the aperture, closure and depth of the ozone hole at each time are computed relative to the total ozone column prevailing during the preceding winter. Figure 8 shows the evolution of the annual cycle of $\Delta \mathrm{TOZ}_{\mathrm{July}}^{\mathrm{SP}}$ as a function of simulated year for run ${ }^{\mathrm{LL}}+\mathrm{VSL}$ and run ${ }^{\mathrm{LL}}$. During the preozone hole era, the typical southern hemispheric natural seasonality is observed, with maximum October ozone columns for run ${ }^{\mathrm{LL}}$ that exceed the values from run ${ }^{\mathrm{LL}}+\mathrm{VSL}$ by $\sim 5 \mathrm{DU}$. Starting in the 1970s, the natural seasonal cycle was disrupted and the natural springtime maximum was replaced by a deep ozone reduction due to the ozone hole formation (Fig. 7b). The maximum $\Delta \mathrm{TOZ}_{\text {July }}^{\mathrm{SP}}$ difference in respect to the preceding winter reaches $-95 \mathrm{DU}$ for $\operatorname{run}^{\mathrm{LL}}+\mathrm{VSL}$ ( -75 DU for run ${ }^{\mathrm{LL}}$ ) during October 2000 (1995-2005 average), showing springtime differences greater than $-30 \mathrm{DU}$ $(-20 \mathrm{DU})$ between September and December all the way from 1980 to 2050. The solid lines in Fig. 8 represent the temporal location of the monthly $\triangle \mathrm{TOZ}_{\text {July }}^{\mathrm{SP}}$ minimum for
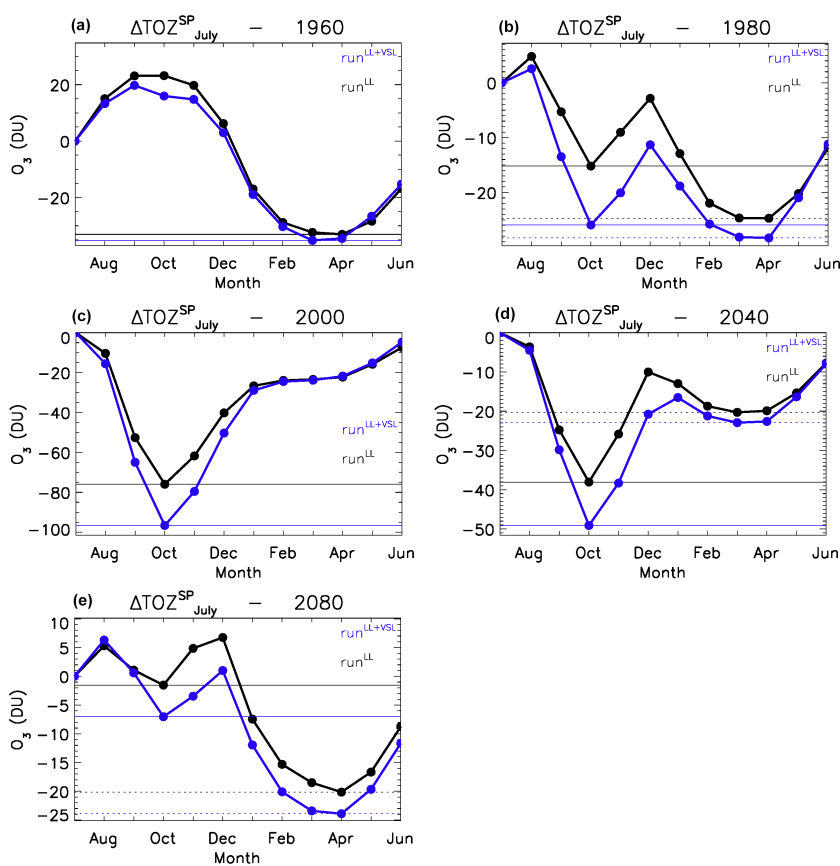

Figure 7. Seasonal variation of $\Delta \mathrm{TOZ}_{\mathrm{July}}^{\mathrm{SP}}$ for $\operatorname{run}^{\mathrm{LL}+\mathrm{VSL}}$ (blue) and run $^{\mathrm{LL}}$ (black) ensemble means at different years: (a) 1960, before the ozone first appeared; (b) 1980, where the appearance of the ozone hole produces a small $\mathrm{TOZ}^{\mathrm{SP}}$ local minimum during spring; (c) 2000, when the ozone hole depth in October maximises; (d) 2040, when $\mathrm{TOZ}^{\mathrm{SP}}$ minimum still appears in spring during the ozone hole recovery timeline; (e) 2080, after the TOZ ${ }^{\text {SP }}$ global minimum has already returned to autumn in its natural seasonal cycle. The solid and dashed horizontal lines highlight the local and global $\mathrm{TOZ}^{\mathrm{SP}}$ minimum for each experiment. $\Delta \mathrm{TOZ}_{\text {July }}^{\mathrm{SP}}$ baseline adjustments were computed relative to the modelled TOZ ${ }^{\mathrm{SP}}$ in July of the preceding winter for each year $\left(\Delta \mathrm{TOZ}_{\mathrm{July}}^{\mathrm{SP}}=\mathrm{TOZ}_{\mathrm{Time}}^{\mathrm{SP}}-\mathrm{TOZ}_{\mathrm{July}}^{\mathrm{SP}}\right)$.

each simulation (white for run ${ }^{\mathrm{LL}}+\mathrm{VSL}$ and black for run ${ }^{\mathrm{LL}}$ ). Starting in $\sim 1981$ the position of the $\Delta \mathrm{TOZ}_{\mathrm{July}}^{\mathrm{SP}}$ annual minimum shifted from April (the radiatively driven autumn minimum) to October (the springtime ozone hole minimum) for $\operatorname{run}^{\mathrm{LL}}+\mathrm{VSL}\left(\sim 1984\right.$ for run $\left.{ }^{\mathrm{LL}}\right)$. Accordingly, the return of the $\Delta \mathrm{TOZ}_{\text {July }}^{\mathrm{SP}}$ annual minimum from October to April is delayed by $\sim 4$ years when $\mathrm{VSL}^{\mathrm{Br}}$ are considered (from 2047 for run ${ }^{\mathrm{LL}}$ to 2051 for run ${ }^{\mathrm{LL}+V S L}$ ). Table 2 shows the independent values for each of the independent ensemble members. Only if the baseline seasonal cycle is superposed below the long-term evolution of the polar stratospheric ozone layer (instead of considering the fixed normalisation to October 1980), the inclusion of biogenic $\mathrm{VSL}^{\mathrm{Br}}$ introduces an extension to the ozone return date of $\sim 6.3 \pm 12.2$ years. Even though this value agrees with the estimations from Yang et al. (2014), it most probably represents a mere coincidence since their time slice computations only considered the changes in the maximum ozone hole depletion under different $\mathrm{VSL}^{\mathrm{Br}}$ loadings, while our analysis highlights 

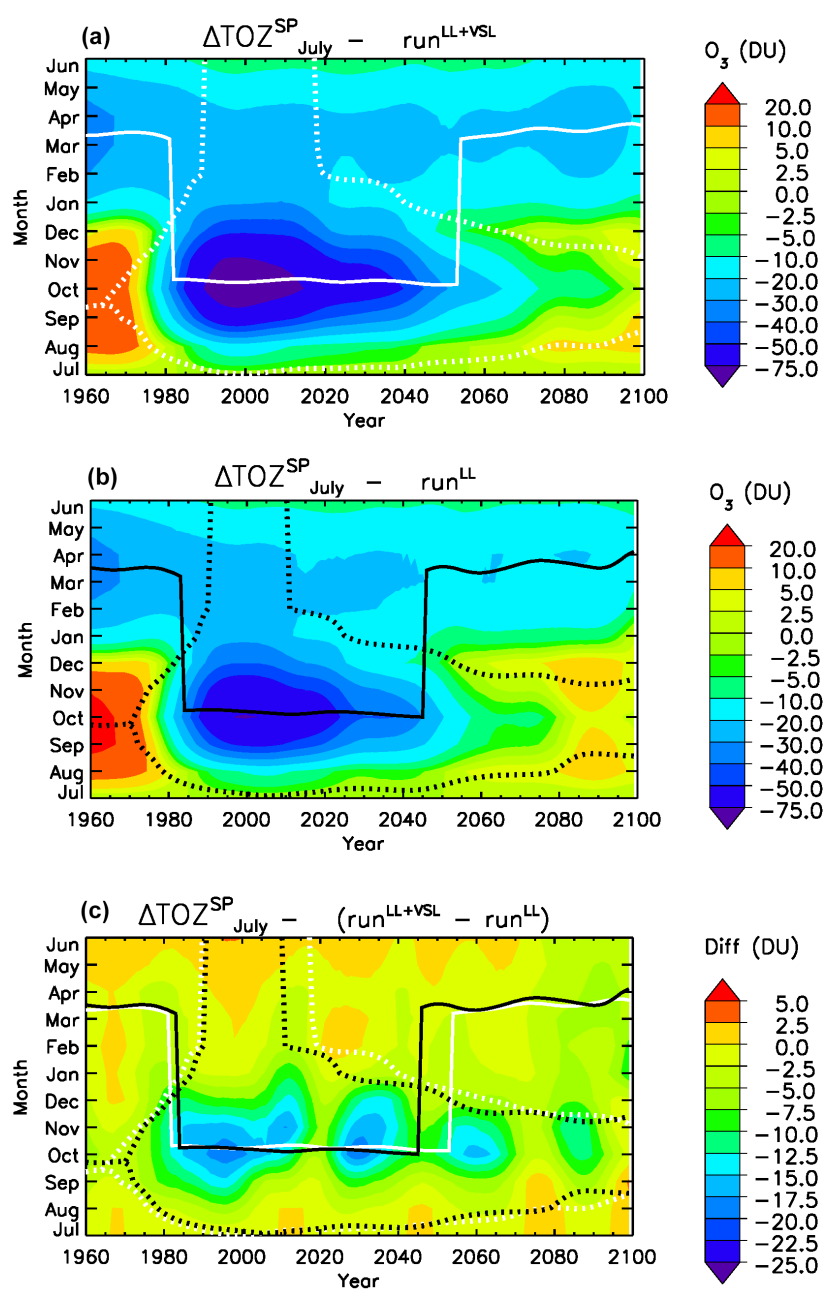

Figure 8. Evolution of $\Delta \mathrm{TOZ}_{\mathrm{July}}^{\mathrm{SP}}$ as a function of the year and month. (a) run ${ }^{\mathrm{LL}}+\mathrm{VSL}$ ensemble mean, (b) run ${ }^{\mathrm{LL}}$ ensemble mean and (c) absolute difference between the simulations. $\Delta \mathrm{TOZ}_{\text {July }}^{\mathrm{SP}}$ baseline adjustments were computed relative to the modelled $\mathrm{TOZ}^{\mathrm{SP}}$ in July of the preceding winter for each year $\left(\Delta \mathrm{TOZ}_{\text {July }}^{\mathrm{SP}}=\mathrm{TOZ}_{\text {Time }}^{\mathrm{SP}}-\mathrm{TOZ}_{\text {July }}^{\mathrm{SP}}\right)$. The solid line indicates the location of the $\Delta \mathrm{TOZ}_{\mathrm{July}}^{\mathrm{SP}}$ annual minimum for each ensemble (white for run ${ }^{\mathrm{VSL}}$ and black for run ${ }^{\text {noVSL}}$ ), while the dashed lines indicate the shifts in the $\Delta \mathrm{TOZ}_{\mathrm{July}}^{\mathrm{SP}}$ local maximums arising on each side of the springtime minimum (see Fig. 7).

the seasonal $\mathrm{TOZ}^{\mathrm{SP}}$ changes within a fully coupled climatic simulation. Note, however, that in agreement with Table 1, the modelled delay on the return date computed considering the changes in the ozone seasonal cycle also lies within the internal model variability.

The dotted lines in Fig. 8 indicate the location of the double local $\Delta \mathrm{TOZ}_{\mathrm{July}}^{\mathrm{SP}}$ maximums observed in Fig. 7b, d-e and allows the determination of how the time span between the ozone hole formation and breaking for each year changes due to $\mathrm{VSL}^{\mathrm{Br}}$ chemistry. Between the mid-1970s and mid-
Table 2. Estimation of the ozone return date based on the period of time where the annual minimum $\Delta \mathrm{TOZ}_{\mathrm{July}}^{\mathrm{SP}}$ is observed during spring for different simulations and ensemble members.

\begin{tabular}{|c|c|c|c|c|}
\hline & \multicolumn{2}{|c|}{$\operatorname{run}^{L L}+V S L$} & \multicolumn{2}{|c|}{$\operatorname{run}^{\mathrm{LL}}$} \\
\hline & Start date & Return date & Start date & Return date \\
\hline & (year) & (year) & (year) & (year) \\
\hline $\operatorname{sim}^{004}$ & 1982 & 2057 & 1983 & 2053 \\
\hline $\operatorname{sim}^{005}$ & 1982 & 2049 & 1984 & 2049 \\
\hline $\operatorname{sim}^{006}$ & 1981 & 2048 & 1985 & 2040 \\
\hline Ensemble & $1981.6 \pm 0.6$ & $2051.3 \pm 4.8$ & $1984.0 \pm 1.0$ & $2047.3 \pm 6.6$ \\
\hline $\begin{array}{l}\text { return } \\
\text { period }\end{array}$ & \multicolumn{2}{|c|}{$(69.6 \pm 4.6)$} & \multicolumn{2}{|c|}{$(63.3 \pm 7.6)$} \\
\hline Shift & \multicolumn{4}{|c|}{$(6.3 \pm 12.2)$} \\
\hline
\end{tabular}

1980s, the seasonal development of the ozone hole for each year rapidly expanded, shifting from a starting point as early as July through a closing date during the summer (December and January). Most notably, the seasonal ozone hole extension during the first half of the century is enlarged by as much as 1 month (from January to February) for run ${ }^{\mathrm{LL}}+\mathrm{VSL}$ between 2020 and 2040. This occurs because the additional source of $\mathrm{VSL}^{\mathrm{Br}}$ produces a deep October ozone minimum on top of the annual seasonal cycle, displacing the second local maximum in between the minima to later dates (see Fig. 7d). During the 2000th decade, the location of the second maximum, representing the closing end of the ozone hole, expands all the way to June of the following year because the ozone hole depletion during October is so large that its impacts persist until the following winter is reached: the year-round depletion of $\triangle \mathrm{TOZ}_{\mathrm{July}}^{\mathrm{SP}}$ expands from 1990 to 2010 for run $^{\mathrm{LL}}$, persisting $\sim 7$ years longer, from 1990 to 2017 for the run ${ }^{\mathrm{LL}}+\mathrm{VSL}$ case. It is worth noting that because the ozone hole seasonal extension is not tied to a fixed TOZ value (as for example $220 \mathrm{DU}$ ) the ozone hole seasonal duration can be computed all the way to year 2100 , even after the October 1980 standard ozone return date has already been achieved. These results indicate that even when $\mathrm{LL}^{\mathrm{Cl}}$ and $\mathrm{LL}^{\mathrm{Br}}$ control the return date of the deepest ozone levels to the 1980 baseline value, the future evolution of $\mathrm{VSL}^{\mathrm{Br}}$ sources are of major importance in determining the future influence of halogen chemistry on the stratospheric Antarctic ozone seasonal cycle.

\subsection{The role of chlorine and bromine ozone loss cycles $\left(\mathrm{ClO}_{x}^{\mathrm{LL}}\right.$ vs. $\left.\mathrm{BrO}_{x}^{\mathrm{LL}}+\mathrm{VSL}\right)$}

Bromine chemical cycles play a well-known role in the halogen-mediated springtime ozone hole formation (McElroy et al., 1986; Lee and Jones, 2002; Salawitch et al., 2005). Here we have used the same definition of odd-oxygen depleting families as in Table 5 from Saiz-Lopez et al. (2014), with the exception of the iodine family, which is not considered in 
this work. Figure 9 shows the temporal evolution of the percentage loss due to each cycle with respect to the total oddoxygen loss rate as well as the partitioning between the chlorine and bromine components within the halogen family. In the following, note that crossed $\mathrm{ClO}_{x}-\mathrm{BrO}_{x}$ cycles have been included in $\mathrm{BrO}_{x}^{\mathrm{LL}}+\mathrm{VSL}$ losses because both simulations include identical stratospheric $\mathrm{LL}^{\mathrm{Cl}}$ loading but a $\sim 5$ pptv difference in total bromine (see Fig. 1).

Between approximately 1980 and 2060 the dominant ozone depleting family within the springtime Antarctic ozone hole is halogens: $\mathrm{ClO}_{x}^{\mathrm{LL}}+\mathrm{BrO}_{x}^{\mathrm{LL}}+\mathrm{VSL}$ surpass the otherwise dominant contribution from $\mathrm{NO}_{x}$ and $\mathrm{HO}_{x}$ cycles (Fig. 9a). For example, during the year of largest ozone depletion (i.e. October 2003), halogens represented more than $90 \%$ of the total odd-oxygen loss at $100 \mathrm{hPa}$, while $\mathrm{NO}_{x}$ and $\mathrm{HO}_{x}$ cycles contributed $\sim 5 \%$ and less than $2 \%$ respectively. By 2050, when the October 1980 baseline ozone return date is expected to occur, the overall $\mathrm{BrO}_{x}^{\mathrm{LL}}+\mathrm{VSL}$ cycles represent $\sim 45 \%$ of the total ozone loss by halogens occurring at $100 \mathrm{hPa}$ (Fig. 9b) and $\sim 35 \%$ when integrated in the stratosphere (Fig. 9c). Even though $\mathrm{ClO}_{x}^{\mathrm{LL}}$ losses represent as much as $80 \%$ of the halogen-mediated ozone loss during the 2000th decade, the additional contribution from VSL ${ }^{\mathrm{Br}}$ drives bromine chemistry $\left(\mathrm{BrO}_{x}^{\mathrm{LL}}+\mathrm{VSL}\right)$ to dominate ozone loss by halogens by approximately 2070 . The contribution of $\mathrm{BrO}_{x}^{\mathrm{LL}}+\mathrm{VSL}$ cycles to ozone loss was also higher than $\mathrm{ClO}_{x}^{\mathrm{LL}}$ before 1975, i.e. before and during the fast increase in anthropogenic CFCs occurred (Fig. 9b). This implies that, although anthropogenic chlorine has controlled and will control the long-term evolution of the springtime stratospheric ozone hole, its overall depleting potential in the lowermost stratosphere is strongly influenced by the total (natu$\mathrm{ral}+$ anthropogenic) stratospheric inorganic bromine, with a non-negligible contribution (up to $\sim 30 \%$ ) from the biogenic $\mathrm{VSL}^{\mathrm{Br}}$ oceanic sources. Within the run ${ }^{\mathrm{LL}}$ experiment, $\mathrm{BrO}_{x}^{\mathrm{LL}}$ cycles never surpass the contribution of $\mathrm{ClO}_{x}^{\mathrm{LL}}$ losses, revealing the significant enhancement of inter-halogen $\mathrm{ClO}_{x}^{\mathrm{LL}}$ $\mathrm{BrO}_{x}^{\mathrm{LL}+\mathrm{VSL}}$ depletion due to the additional source of natural $\mathrm{VSL}^{\mathrm{Br}}$.

There is a clear variation in the height at which $\mathrm{ClO}_{x}$ and $\mathrm{BrO}_{x}^{\mathrm{LL}}+\mathrm{VSL}$ cycles produce their maximum destruction, as well as the period of time when the losses by each family dominate with respect to the others. For example, pure $\mathrm{ClO}_{x}^{\mathrm{LL}}$ cycles account for more than $80 \%$ of the total halogen losses above $10 \mathrm{hPa}$ during the whole 21 st century, while $\mathrm{BrO}_{x}^{\mathrm{LL}}+\mathrm{VSL}$ cycles maximise close to the tropopause. Figure 10 shows that during the Antarctic spring, stratospheric bromine chemistry below $50 \mathrm{hPa}$ has been at least as important as chlorine before and after the ozone hole era. Thus, the future evolution of stratospheric $\mathrm{LL}^{\mathrm{Cl}}$ levels will control the ozone hole return date, but the role played by $\mathrm{VSL}^{\mathrm{Br}}$ by that time will be as large as the one arising from $L^{\mathrm{Br}}$. This effect will be most evident within the lower stratospheric levels: bromine is globally $\sim 60$ times more efficient than chlorine in depleting ozone (Daniel et al., 1999; Sinnhuber et
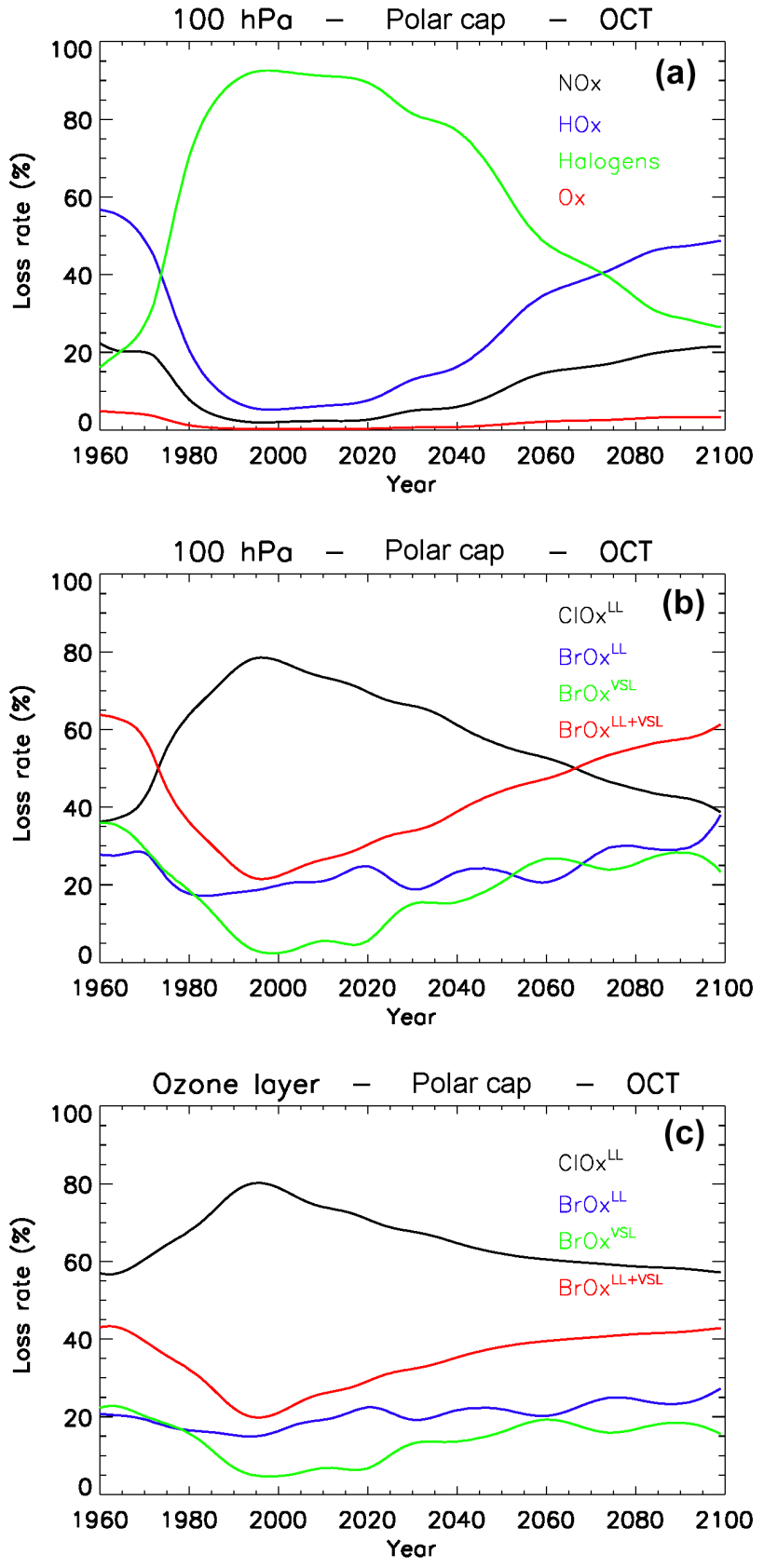

Figure 9. Temporal evolution of the October mean odd-oxygen loss rates within the southern polar cap. (a) Percentage contribution of each ozone depleting family $\left(\mathrm{HO}_{x}, \mathrm{NO}_{x}, \mathrm{O}_{x}\right.$ and Halogens) in respect to the total loss rate at $100 \mathrm{hPa}(\sim 15 \mathrm{~km})$, (b) percentage contribution of each halogen family $\left(\mathrm{ClO}_{x}, \mathrm{BrO}_{x}^{\mathrm{LL}}, \mathrm{BrO}_{x}^{\mathrm{VSL}}\right.$ and $\mathrm{BrO}_{x}^{\mathrm{LL}}+\mathrm{VSL}$ ) in respect to the whole halogen loss rate at $100 \mathrm{hPa}$ and (c) The same as panel (b) but vertically integrated within the lower stratosphere (i.e. in-between the white lines shown in Fig. 6). Ensemble mean values are shown. 

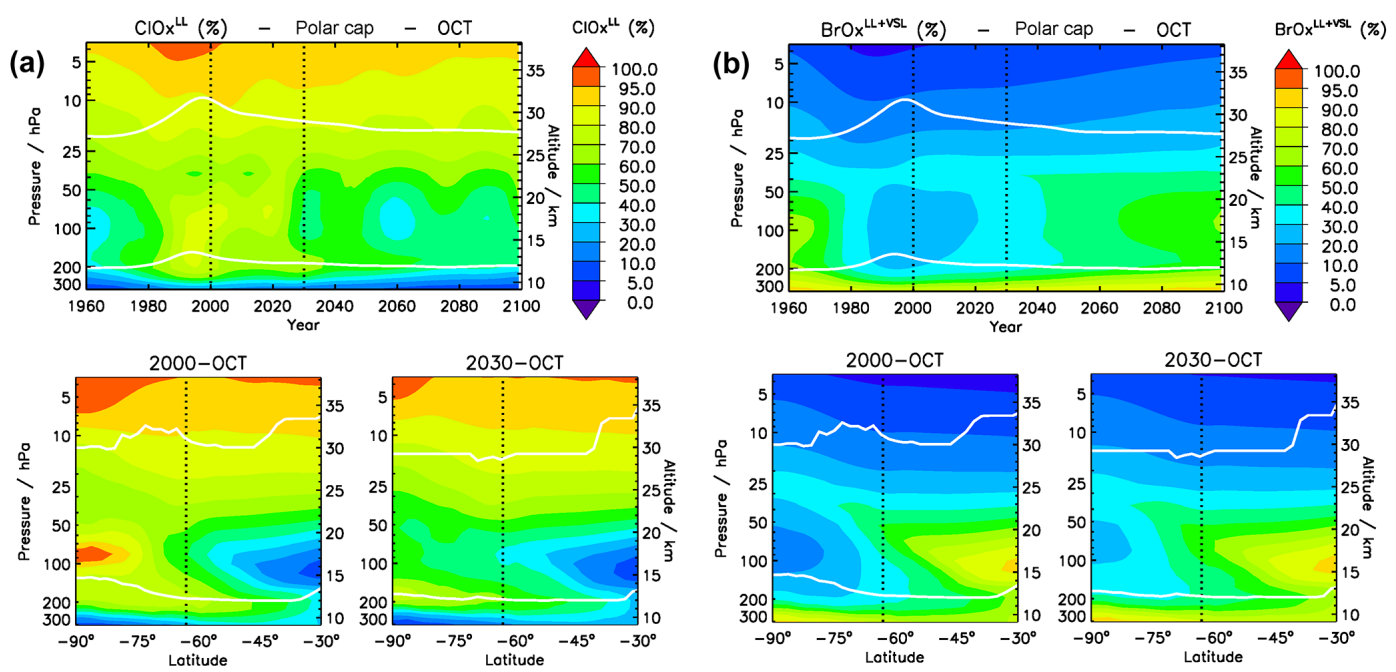

Figure 10. Evolution of the odd-oxygen loss rate vertical profiles (VP) within the southern polar cap. The percentage contribution of each family in respect to the whole halogen loss during October is shown for (a) the $\mathrm{ClO}_{x}^{\mathrm{LL}}$ family, and (b) the $\mathrm{BrO}_{x}^{\mathrm{LL}+\mathrm{VSL}}$ family. The inset below each VP shows the October zonal mean vertical distributions of odd-oxygen losses during the 2000th (1995-2005 mean, left) and 2030th (2025-2035 mean, right) decades. All results are for the run ${ }^{\mathrm{LL}}+\mathrm{VSL}$ ensemble. The lower solid white line indicates the location of the tropopause, while the higher solid line indicates the height where $\mathrm{O}_{3}$ number density equals its value at the tropopause.

(a)

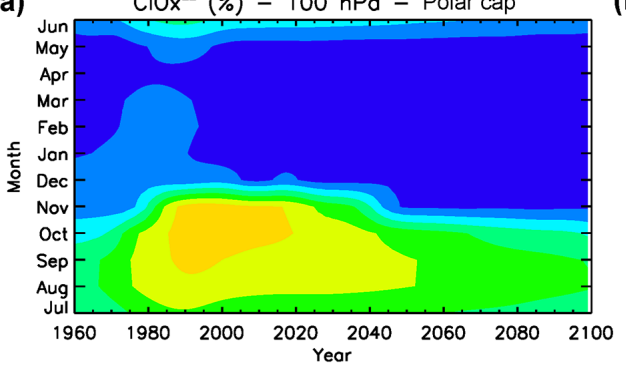

(c)

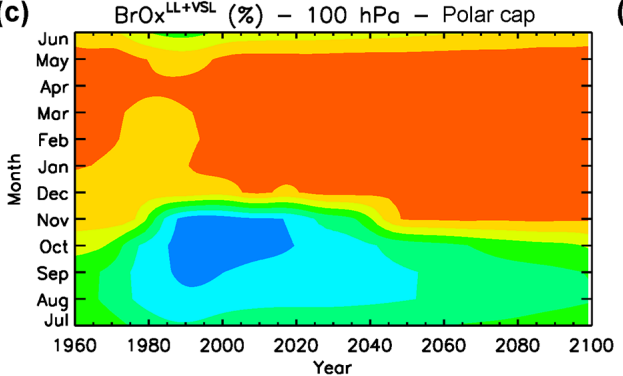

(b)

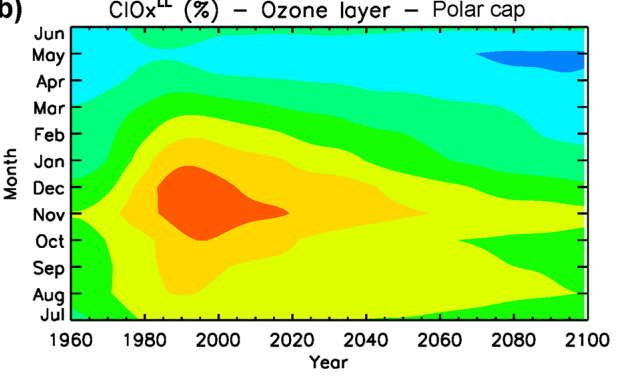

(d)

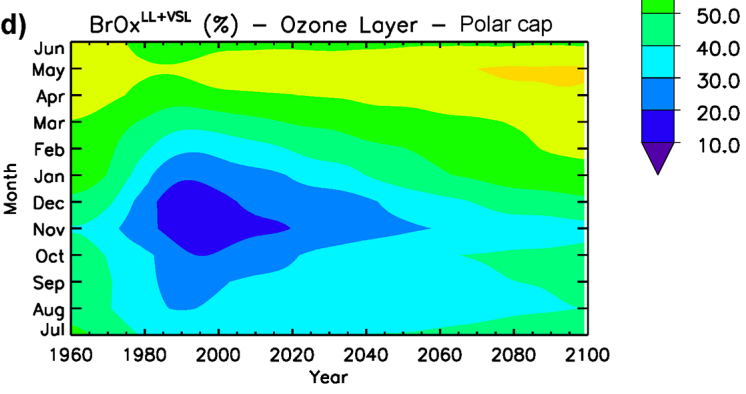

Figure 11. Evolution of the halogen-catalysed odd-oxygen loss rates as a function of the year and month for the $\mathrm{ClO}_{x}^{\mathrm{LL}}$ family (top row) and the $\mathrm{BrO}_{x}^{\mathrm{LL}}+\mathrm{VSL}$ family (bottom row). The left column shows loss rate values at $100 \mathrm{hPa}(\sim 15 \mathrm{~km})$, while in the right column the loss rates were vertically integrated within the lower stratosphere (i.e. in-between the white lines shown in Fig. 10). Results are for the run ${ }^{\mathrm{L}}+\mathrm{VSL}$ ensemble. 
al., 2009), but its efficacy relies mostly on the background levels of stratospheric chlorine and the prevailing temperature affecting the rate of the inter-halogen crossed reactions (Saiz-Lopez and Fernandez, 2016). Additionally, the extent of $\mathrm{ClO}_{x}^{\mathrm{LL}}$ depletion within the Antarctic vortex relies on the occurrence of heterogeneous activation of chlorine reservoir species in polar stratospheric clouds, which in turn depend on ambient temperature. Then, the efficiency of $\mathrm{BrO}_{x}^{\mathrm{LL}+\mathrm{VSL}_{-}}$ depleting cycles relative to chlorine is reduced in the colder lower stratosphere at high latitudes during the 2000th decade (see lower panels in Fig. 10), while the $\mathrm{BrO}_{x}^{\mathrm{LL}+\mathrm{VSL}}$ contribution is larger at mid-latitudes and increases in importance as we move forward in time.

The representation of the $\mathrm{ClO}_{x}^{\mathrm{LL}}$ and $\mathrm{BrO}_{x}^{\mathrm{LL}+\mathrm{VSL}}$ contributions shown in Fig. 11 allows the address of two interesting features related to the seasonal and long-term evolution of lower stratospheric Antarctic ozone. For any fixed year during the ozone hole era, the relative contribution of bromine chemistry reaches a minimum during austral spring, while it increases during the summer and autumn months. For example, the $\mathrm{BrO}_{x}^{\mathrm{LL}}$ contribution to total halogen loss at $100 \mathrm{hPa}$ for 2000 is $25 \%$ during October, $65 \%$ in December and greater than $80 \%$ by March. Thus, if the Antarctic return date delay is computed considering the baseline 1980 value for the autumn months, a greater impact from $\mathrm{VSL}^{\mathrm{Br}}$ is observed (see Fig. 3c). Accordingly, the evaluation of the long-term impact of $\mathrm{ClO}_{x}^{\mathrm{LL}}$ and $\mathrm{BrO}_{x}^{\mathrm{LL}}+\mathrm{VSL}$ cycles on the evolution of Antarctic ozone changes abruptly if we focus on the autumn months instead of considering the October mean. In the lower stratosphere, chlorine chemistry is dramatically enhanced during October due to the formation of the Antarctic ozone hole, but during summer and autumn $\mathrm{ClO}_{x}^{\mathrm{LL}}$ losses decrease, representing less than $20 \%$ of the total halogen loss (March mean) during the 21st century.

\section{Discussion and concluding remarks}

We have shown that biogenic $\mathrm{VSL}^{\mathrm{Br}}$ have a profound impact on the depth, size and vertical distribution of the springtime Antarctic ozone hole. The inclusion of $\mathrm{VSL}^{\mathrm{Br}}$ improves the quantitative 1980-2010 model-satellite agreement of $\mathrm{TOZ}^{\mathrm{SP}}$, and it is necessary to capture the lowest October mean ozone hole values. Our model results also show that, even when the maximum springtime depletion is increased by the inclusion of $\mathrm{VSL}^{\mathrm{Br}}$, the future recovery of Antarctic ozone to the prevailing levels before 1980 is primarily driven by the evolution of the dominant $\mathrm{LL}^{\mathrm{Cl}}$ and $\mathrm{LL}^{\mathrm{Br}}$ sources, i.e. $\mathrm{VSL}^{\mathrm{Br}}$ sources do not significantly change the estimated return date. This can be explained considering the larger impact of bromine chemistry during periods of high inorganic chlorine loading and the background impact of the additional bromine on the past global stratosphere. Other chemistry climate modelling studies estimated a decade enlargement of the expected return date based on a single member simulation
(Oman et al., 2016). Those studies considered an approximate $\mathrm{VSL}^{\mathrm{Br}}$ approach, increasing the $\mathrm{CH}_{3} \mathrm{Br}$ lower boundary condition by $\sim 5$ pptv, while here we performed six independent simulations, including geographically distributed time-dependent VSL ${ }^{\mathrm{Br}}$ oceanic sources. Note, however, that free-running ocean interactive simulations like the ones performed in this work possess a very large model internal variability $(\sim 10$ years difference between the shortest and largest return date for run ${ }^{\mathrm{LL}}+\mathrm{VSL}$ ); therefore, more ensemble members might be required to better address the important issue of the return date. Additional simulations including the explicit representation of VSL bromocarbons in chemistryclimate models representing the whole stratosphere would help to further reduce model uncertainties. The $\mathrm{TOZ}^{\mathrm{SP}}$ minimum and the ozone hole depth in the lower stratosphere are both increased by 14 and $40 \%$ respectively when the additional source of biogenic bromine is considered. This effect is more pronounced in the periphery of the ozone hole and within the heights of smaller ozone densities. Interestingly, biogenic bromine produces an enlargement of the OHA of 5 million $\mathrm{km}^{2}$, equivalent to that of the recently estimated Antarctic ozone healing due to the implementation of the Montreal Protocol. This large effect of oceanic $\mathrm{VSL}^{\mathrm{Br}}$ on the OHA highlights the importance of including biogenic bromine in climate assessments of the future Antarctic ozone layer. As the anthropogenic emissions of $\mathrm{LL}^{\mathrm{Cl}}$ and $\mathrm{LL}^{\mathrm{Br}}$ are projected to decrease in the future following the Montreal Protocol, the natural $\mathrm{VSL}^{\mathrm{Br}}$ relative contribution will represent as much as $40 \%$ of stratospheric bromine throughout the 21 st century, or even more if the oceanic VSL ${ }^{\mathrm{Br}}$ source strength and deep convection tropical injection increase in the near future (Hossaini et al., 2012; Leedham et al., 2013). Indeed, enhanced bromine $\mathrm{BrO}_{x}^{\mathrm{LL}}+\mathrm{VSL}_{\text {cycles will dominate }}$ the chemistry of the lowermost stratosphere over Antarctica before a complete recovery of the global ozone layer from $\mathrm{LL}^{\mathrm{Br}}$ and $\mathrm{LL}^{\mathrm{Cl}}$ has occurred. Hence, oceanic VSL ${ }^{\mathrm{Br}}$ possess leverage to significantly influence the future evolution of the Antarctic ozone layer.

\section{Data availability}

Computing resources (ark:/85065/d7wd3xhc) were provided by the Climate Simulation Laboratory at NCAR's Computational and Information Systems Laboratory (CISL), sponsored by the NSF. The outputs from model simulations used here are available upon request.

\section{The Supplement related to this article is available online at doi:10.5194/acp-17-1673-2017-supplement.}

Competing interests. The authors declare that they have no conflict of interest. 
Acknowledgements. We would like to thank Greg Bodeker of Bodeker Scientific, funded by the New Zealand Deep South National Science Challenge, for providing the combined total column ozone database. This work was supported by the Consejo Superior de Investigaciones Científicas (CSIC), Spain. The National Center for Atmospheric Research (NCAR) is funded by the National Science Foundation (NSF). Computing resources (ark:/85065/d7wd3xhc) were provided by the Climate Simulation Laboratory at NCAR's Computational and Information Systems Laboratory (CISL), sponsored by the NSF. The CESM project (which includes CAM-Chem) is supported by the NSF and the Office of Science (BER) of the US Department of Energy. Rafael P. Fernandez would like to thank Pablo Cremades for his technical help with post-processing the output data, and to CONICET, FCEN-UNCuyo and UTN-FRMendoza for financial support.

Edited by: Peter Hess

Reviewed by: B.-M. Sinnhuber and one anonymous referee

\section{References}

Aschmann, J. and Sinnhuber, B.-M.: Contribution of very shortlived substances to stratospheric bromine loading: uncertainties and constraints, Atmos. Chem. Phys., 13, 1203-1219, doi:10.5194/acp-13-1203-2013, 2013.

Aschmann, J., Sinnhuber, B.-M., Chipperfield, M. P., and Hossaini, R.: Impact of deep convection and dehydration on bromine loading in the upper troposphere and lower stratosphere, Atmos. Chem. Phys., 11, 2671-2687, doi:10.5194/acp-11-2671-2011, 2011.

Austin, J., Struthers, H., Scinocca, J., Plummer, D. A., Akiyoshi, H., Baumgaertner, A. J. G., Bekki, S., Bodeker, G. E., Braesicke, P., Brühl, C., Butchart, N., Chipperfield, M. P., Cugnet, D., Dameris, M., Dhomse, S., Frith, S., Lamarque, J. F., Langematz, U., Mancini, E., Marchand, M., and Michou, M.: Chemistryclimate model simulations of spring Antarctic ozone, J. Geophys. Res., 115, D00M11, doi:10.1029/2009JD013577, 2010.

Bekki, S., Rap, A., Poulain, V., Dhomse, S., Marchand, M., Lefevre, F., Forster, P. M., Szopa, S., and Chipperfield, M. P.: Climate impact of stratospheric ozone recovery, Geophys. Res. Lett., 40, 2796-2800, doi:10.1002/grl.50358, 2013.

Bodeker, G. E., Shiona, H., and Eskes, H.: Indicators of Antarctic ozone depletion, Atmos. Chem. Phys., 5, 2603-2615, doi:10.5194/acp-5-2603-2005, 2005.

Braesicke, P., Keeble, J., Yang, X., Stiller, G., Kellmann, S., Abraham, N. L., Archibald, A., Telford, P., and Pyle, J. A.: Circulation anomalies in the Southern Hemisphere and ozone changes, Atmos. Chem. Phys., 13, 10677-10688, doi:10.5194/acp-1310677-2013, 2013.

Butler, J. H., King, D. B., Lobert, J. M., Montzka, S. A., YvonLewis, S. a., Hall, B. D., Warwick, N. J., Mondeel, D. J., Aydin, M., and Elkins, J. W.: Oceanic distributions and emissions of short-lived halocarbons, Global Biogeochem. Cy., 21, GB1023, doi:10.1029/2006GB002732, 2007.

Chipperfield, M. P., Dhomse, S. S., Feng, W., McKenzie, R. L., Velders, G. J. M., and Pyle, J. A: Quantifying the ozone and ul- traviolet benefits already achieved by the Montreal Protocol, Nat. Comm., 6, 7233, doi:10.1038/ncomms8233, 2015.

Daniel, J. S., Solomon, S., Portmann, R. W., and Garcia, R. R.: Stratospheric ozone destruction: The importance of bromine relative to chlorine, J. Geophys. Res., 104, 23871, doi:10.1029/1999JD900381, 1999.

Eyring, V., Waugh, D. W., Bodeker, G. E., Cordero, E., Akiyoshi, H., Austin, J., Beagley, S. R., Boville, B. A., Braesicke, P., Brühl, C., Butchart, N., Chipperfield, M. P., Dameris, M., Deckert, R., Deushi, M., Frith, S. M., Garcia, R. R., Gettelman, A., Giorgetta, M. a., Kinnison, D. E., Mancini, E., Manzini, E., Marsh, D. R., Matthes, S., Nagashima, T., Newman, P. A., Nielsen, J. E., Pawson, S., Pitari, G., Plummer, D. A., Rozanov, E., Schraner, M., Scinocca, J. F., Semeniuk, K., Shepherd, T. G., Shibata, K., Steil, B., Stolarski, R. S., Tian, W., and Yoshiki, M.: Multimodel projections of stratospheric ozone in the 21st century, J. Geophys. Res., 112, D16303, doi:10.1029/2006JD008332, 2007.

Eyring, V., Cionni, I., Bodeker, G. E., Charlton-Perez, A. J., Kinnison, D. E., Scinocca, J. F., Waugh, D. W., Akiyoshi, H., Bekki, S., Chipperfield, M. P., Dameris, M., Dhomse, S., Frith, S. M., Garny, H., Gettelman, A., Kubin, A., Langematz, U., Mancini, E., Marchand, M., Nakamura, T., Oman, L. D., Pawson, S., Pitari, G., Plummer, D. A., Rozanov, E., Shepherd, T. G., Shibata, K., Tian, W., Braesicke, P., Hardiman, S. C., Lamarque, J. F., Morgenstern, O., Pyle, J. A., Smale, D., and Yamashita, Y.: Multimodel assessment of stratospheric ozone return dates and ozone recovery in CCMVal-2 models, Atmos. Chem. Phys., 10, 94519472, doi:10.5194/acp-10-9451-2010, 2010a.

Eyring, V., Cionni, I., Lamarque, J. F., Akiyoshi, H., Bodeker, G. E., Charlton-Perez, A. J., Frith, S. M., Gettelman, a., Kinnison, D. E., Nakamura, T., Oman, L. D., Pawson, S., and Yamashita, Y.: Sensitivity of 21 st century stratospheric ozone to greenhouse gas scenarios, Geophys. Res. Lett., 37, L16807, doi:10.1029/2010GL044443, 2010b.

Eyring, V., Lamarque, J.-F., Hess, P., Arfeuille, F., Bowman, K., Chipperfield, M. P., Duncan, B., Fiore, A., Gettelman, A., Giorgetta, M. A., Granier, C., Hegglin, M., Kinnison, D., Kunze, M., Langematz, U., Luo, B., Martin, R., Matthes, K., Newman, P. A., Peter, T., Robock, A., Ryerson, T., Saiz-Lopez, A., Salawitch, R., Schultz, M., Shepherd, T. G., Shindell, D., Stähelin, J., Tegtmeier, S., Thomason, L., Tilmes, S., Vernier, J.-P., Waugh, D. W. and Young, P. J.: Overview of IGAC/SPARC Chemistry-Climate Model Initiative (CCMI) Community Simulations in Support of Upcoming Ozone and Climate Assessments, SPARC Newsl., 40, 48-66, 2013.

Farman, J. C., Gardiner, B. G., and Shanklin, J. D.: Large losses of total ozone in Antarctica reveal seasonal $\mathrm{ClO}_{x} / \mathrm{NO}_{x}$ interaction, Nature, 315, 207-210, doi:10.1038/315207a0, 1985.

Feng, W., Chipperfield, M. P., Dorf, M., Pfeilsticker, K., and Ricaud, P.: Mid-latitude ozone changes: studies with a 3-D CTM forced by ERA-40 analyses, Atmos. Chem. Phys., 7, 2357-2369, doi:10.5194/acp-7-2357-2007, 2007

Fernandez, R. P., Salawitch, R. J., Kinnison, D. E., Lamarque, J.-F., and Saiz-Lopez, A.: Bromine partitioning in the tropical tropopause layer: implications for stratospheric injection, Atmos. Chem. Phys., 14, 13391-13410, doi:10.5194/acp-1413391-2014, 2014.

Hegglin, M. I., Lamarque, J.-F., Eyring, V., Hess, P., Young, P. J., Fiore, A. M., Myhre, G., Nagashima, T., Ryerson, T., Shepherd, 
T. G., and Waugh, D. W.: IGAC/SPARC Chemistry-Climate Model Initiative (CCMI) 2014 Science Workshop, SPARC Newsl., 43, 32-35, 2014.

Hossaini, R., Chipperfield, M. P., Dhomse, S., Ordóñez, C., Saiz-Lopez, A., Abraham, N. L., Archibald, A., Braesicke, P., Telford, P., Warwick, N., Yang, X., and Pyle, J.: Modelling future changes to the stratospheric source gas injection of biogenic bromocarbons, Geophys. Res. Lett., 39, L20813, doi:10.1029/2012GL053401, 2012.

Hossaini, R., Patra, P. K., Leeson, A. A., Krysztofiak, G., Abraham, N. L., Andrews, S. J., Archibald, A. T., Aschmann, J., Atlas, E. L., Belikov, D. A., Bönisch, H., Carpenter, L. J., Dhomse, S., Dorf, M., Engel, A., Feng, W., Fuhlbrügge, S., Griffiths, P. T., Harris, N. R. P., Hommel, R., Keber, T., Krüger, K., Lennartz, S. T., Maksyutov, S., Mantle, H., Mills, G. P., Miller, B., Montzka, S. A., Moore, F., Navarro, M. A., Oram, D. E., Pfeilsticker, K., Pyle, J. A., Quack, B., Robinson, A. D., Saikawa, E., Saiz-Lopez, A., Sala, S., Sinnhuber, B.-M., Taguchi, S., Tegtmeier, S., Lidster, R. T., Wilson, C., and Ziska, F.: A multi-model intercomparison of halogenated very short-lived substances (TransComVSLS): linking oceanic emissions and tropospheric transport for a reconciled estimate of the stratospheric source gas injection of bromine, Atmos. Chem. Phys., 16, 9163-9187, doi:10.5194/acp16-9163-2016, 2016.

Kerkweg, A., Jöckel, P., Warwick, N., Gebhardt, S., Brenninkmeijer, C. A. M., and Lelieveld, J.: Consistent simulation of bromine chemistry from the marine boundary layer to the stratosphere - Part 2: Bromocarbons, Atmos. Chem. Phys., 8, 5919-5939, doi:10.5194/acp-8-5919-2008, 2008.

Kinnison, D. E., Brasseur, G. P., Walters, S., Garcia, R. R., Marsh, D. R., Sassi, F., Harvey, V. L., Randall, C. E., Emmons, L., Lamarque, J. F., Hess, P., Orlando, J. J., Tie, X. X., Randel, W., Pan, L. L., Gettelman, A., Granier, C., Diehl, T., Niemeier, U., and Simmons, A. J.: Sensitivity of chemical tracers to meteorological parameters in the MOZART-3 chemical transport model, J. Geophys. Res., 112, D20302, doi:10.1029/2006JD007879, 2007

Lamarque, J.-F., Kinnison, D. E., Hess, P. G., and Vitt, F. M.: Simulated lower stratospheric trends between 1970 and 2005: Identifying the role of climate and composition changes, J. Geophys. Res., 113, D12301, doi:10.1029/2007JD009277, 2008.

Lamarque, J.-F., Emmons, L. K., Hess, P. G., Kinnison, D. E., Tilmes, S., Vitt, F., Heald, C. L., Holland, E. A., Lauritzen, P. H., Neu, J., Orlando, J. J., Rasch, P. J., and Tyndall, G. K.: CAM-chem: description and evaluation of interactive atmospheric chemistry in the Community Earth System Model, Geosci. Model Dev., 5, 369-411, doi:10.5194/gmd-5-369-2012, 2012

Lee, A. A. M. and Jones, R.: Diagnosing ozone loss in the extratropical lower stratosphere, J. Geophys. Res., 107, 4110, doi:10.1029/2001JD000538, 2002.

Leedham, E. C., Hughes, C., Keng, F. S. L., Phang, S.-M., Malin, G., and Sturges, W. T.: Emission of atmospherically significant halocarbons by naturally occurring and farmed tropical macroalgae, Biogeosciences, 10, 3615-3633, doi:10.5194/bg-10-36152013, 2013.

Liang, Q., Atlas, E., Blake, D., Dorf, M., Pfeilsticker, K., and Schauffler, S.: Convective transport of very short lived bromo- carbons to the stratosphere, Atmos. Chem. Phys., 14, 5781-5792, doi:10.5194/acp-14-5781-2014, 2014.

McElroy, M. B., Salawitch, R. J., Wofsy, S. C., and Logan, J. A.: Reductions of Antarctic ozone due to synergistic interactions of chlorine and bromine, Nature, 321, 759-762, 1986.

Molina, M. J. and Rowland, F. S.: Stratospheric sink for chlorofluoromethanes: chlorine atomc-atalysed destruction of ozone, Nature, 249, 810-812, doi:10.1038/249810a0, 1974.

Montzka, S. A., Reimann, S., Engel, A., Krüger, K., O’Doherty, S., and Sturges, W. T.: Ozone-Depleting Substances (ODSs) and Related Chemicals, in: Scientific Assessment of Ozone Depletion: 2010, Global Ozone Research and Monitoring Project-Report No. 52, Geneva, Switzerland, 2011.

Navarro, M. A., Atlas, E. L., Saiz-lopez, A., Rodriguez-lloveras, X., Kinnison, D. E., Lamarque, J., Tilmes, S., Filus, M., Harris, N. R. P., Meneguz, E., Ashfold, M. J., Manning, A. J., Cuevas, C. A., Schauffler, S. M., and Valeria Donets: Airborne measurements of organic bromine compounds in the Pacific tropical tropopause layer, P. Natl. Acad. Sci. USA, 112, 13789-13793, doi:10.1073/pnas.1522889113, 2015.

Oman, L. D., Douglass, A. R., Salawitch, R. J., Canty, T. P., Ziemke, J. R., and Manyin, M.: The effect of representing bromine from VSLS on the simulation and evolution of Antarctic ozone, Geophys. Res. Lett., 43, 9869-9876, doi:10.1002/2016GL070471, 2016.

Ordóñez, C., Lamarque, J.-F., Tilmes, S., Kinnison, D. E., Atlas, E. L., Blake, D. R., Sousa Santos, G., Brasseur, G., and Saiz-Lopez, A.: Bromine and iodine chemistry in a global chemistry-climate model: description and evaluation of very short-lived oceanic sources, Atmos. Chem. Phys., 12, 1423-1447, doi:10.5194/acp12-1423-2012, 2012.

Saiz-Lopez, A. and Fernandez, R. P.: On the formation of tropical rings of atomic halogens: Causes and implications, Geophys. Res. Lett., 43, 2928-2935, 2016.

Saiz-Lopez, A., Lamarque, J.-F., Kinnison, D. E., Tilmes, S., Ordóñez, C., Orlando, J. J., Conley, A. J., Plane, J. M. C., Mahajan, A. S., Sousa Santos, G., Atlas, E. L., Blake, D. R., Sander, S. P., Schauffler, S., Thompson, A. M., and Brasseur, G.: Estimating the climate significance of halogen-driven ozone loss in the tropical marine troposphere, Atmos. Chem. Phys., 12, 3939-3949, doi:10.5194/acp-12-3939-2012, 2012.

Saiz-Lopez, A., Fernandez, R. P., Ordóñez, C., Kinnison, D. E., Gómez Martín, J. C., Lamarque, J.-F., and Tilmes, S.: Iodine chemistry in the troposphere and its effect on ozone, Atmos. Chem. Phys., 14, 13119-13143, doi:10.5194/acp-1413119-2014, 2014.

Salawitch, R. J., Weisenstein, D. K., Kovalenko, L. J., Sioris, C. E., Wennberg, P. O., Chance, K., Ko, M. K. W., and McLinden, C. A.: Sensitivity of ozone to bromine in the lower stratosphere, Geophys. Res. Lett., 32, L05811, doi:10.1029/2004GL021504, 2005.

Salawitch, R. J., Canty, T., Kurosu, T., Chance, K., Liang, Q., da Silva, A., Pawson, S., Nielsen, J. E., Rodriguez, J. M., Bhartia, P. K., Liu, X., Huey, L. G., Liao, J., Stickel, R. E., Tanner, D. J., Dibb, J. E., Simpson, W. R., Donohoue, D., Weinheimer, A., Flocke, F., Knapp, D., Montzka, D., Neuman, J. A., Nowak, J. B., Ryerson, T. B., Oltmans, S., Blake, D. R., Atlas, E. L., Kinnison, D. E., Tilmes, S., Pan, L. L., Hendrick, F., Van Roozendael, M., Kreher, K., Johnston, P. V., Gao, R. S., Johnson, B., Bui, T. 
P., Chen, G., Pierce, R. B., Crawford, J. H., and Jacob, D. J.: A new interpretation of total column BrO during Arctic spring, Geophys. Res. Lett., 37, L21805, doi:10.1029/2010GL043798, 2010.

Sinnhuber, B.-M. and Meul, S.: Simulating the impact of emissions of brominated very short lived substances on past stratospheric ozone trends, Geophys. Res. Lett., 2449-2456, doi:10.1002/2014GL062975, 2015.

Sinnhuber, B.-M., Sheode, N., Sinnhuber, M., Chipperfield, M. P., and Feng, W.: The contribution of anthropogenic bromine emissions to past stratospheric ozone trends: a modelling study, Atmos. Chem. Phys., 9, 2863-2871, doi:10.5194/acp-9-2863-2009, 2009.

Solomon, S.: Stratospheric ozone depletion: A review of concepts and history, Rev. Geophys., 37, 275-316, doi:10.1029/1999RG900008, 1999.

Solomon, S., Kinnison, D., Bandoro, J., and Garcia, R.: Simulation of polar ozone depletion?: An update, J. Geophys. Res.-Atmos., 120, 7958-7974, doi:10.1002/2015JD023365, 2015.

Solomon, S., Ivy, D. J., Kinnison, D., Mills, M. J., Neely, R. R., and Schmidt, A.: Emergence of healing in the Antarctic ozone layer, Science, 353, 269-274, doi:10.1126/science.aae0061, 2016.

Tilmes, S., Lamarque, J.-F., Emmons, L. K., Kinnison, D. E., Ma, P.-L., Liu, X., Ghan, S., Bardeen, C., Arnold, S., Deeter, M., Vitt, F., Ryerson, T., Elkins, J. W., Moore, F., Spackman, J. R., and Val Martin, M.: Description and evaluation of tropospheric chemistry and aerosols in the Community Earth System Model (CESM1.2), Geosci. Model Dev., 8, 1395-1426, doi:10.5194/gmd-8-13952015, 2015.
Tilmes, S., Lamarque, J.-F., Emmons, L. K., Kinnison, D. E., Marsh, D., Garcia, R. R., Smith, A. K., Neely, R. R., Conley, A., Vitt, F., Val Martin, M., Tanimoto, H., Simpson, I., Blake, D. R., and Blake, N.: Representation of the Community Earth System Model (CESM1) CAM4-chem within the ChemistryClimate Model Initiative (CCMI), Geosci. Model Dev., 9, 18531890, doi:10.5194/gmd-9-1853-2016, 2016.

Warwick, N. J., Pyle, J. A., and Shallcross, D. E.: Global Modelling of the Atmospheric Methyl Bromide Budget, J. Atmos. Chem., 54, 133-159, doi:10.1007/s10874-006-9020-3, 2006.

Wegner, T., Kinnison, D. E., Garcia, R. R., and Solomon, S.: Simulation of polar stratospheric clouds in the specified dynamics version of the whole atmosphere community climate model, J. Geophys. Res.-Atmos., 118, 4991-5002, doi:10.1002/jgrd.50415, 2013.

WMO: Scientific Assessment of Ozone Depletion: 2010, Global Ozone Research and Monitoring Project-Report No. 52, Geneva, Switzerland, 2011.

WMO: Scientific Assessment of Ozone Depletion: 2010, Global Ozone Research and Monitoring Project-Report No. 55, World Meteorological Organization, Geneva, Switzerland, 2014.

Yang, X., Abraham, N. L., Archibald, A. T., Braesicke, P., Keeble, J., Telford, P. J., Warwick, N. J., and Pyle, J. A.: How sensitive is the recovery of stratospheric ozone to changes in concentrations of very short-lived bromocarbons?, Atmos. Chem. Phys., 14, 10431-10438, doi:10.5194/acp-14-10431-2014, 2014. 